Nonlin. Processes Geophys., 20, 825-839, 2013

www.nonlin-processes-geophys.net/20/825/2013/

doi:10.5194/npg-20-825-2013

(c) Author(s) 2013. CC Attribution 3.0 License.

(c) (i)

\title{
Momentum and buoyancy transfer in atmospheric turbulent boundary layer over wavy water surface - Part 1: Harmonic wave
}

\author{
Yu. I. Troitskaya ${ }^{1,4}$, E. V. Ezhova ${ }^{1,4}$, and S. S. Zilitinkevich ${ }^{2,3,4,5,6}$ \\ ${ }^{1}$ Institute of Applied Physics RAS, Nizhniy Novgorod, Russia \\ ${ }^{2}$ Finnish Meteorological Institute, Helsinki, Finland \\ ${ }^{3}$ Department of Physics, University of Helsinki, Helsinki, Finland \\ ${ }^{4}$ Department of Radiophysics, N.I. Lobachevski State University of Nizhniy Novgorod, Nizhniy Novgorod, Russia \\ ${ }^{5}$ Institute of Geography RAS, Moscow, Russia \\ ${ }^{6}$ Nansen Environmental and Remote Sensing Centre, Bergen, Norway
}

Correspondence to: Yu. I. Troitskaya (yuliya@ hydro.appl.sci-nnov.ru)

Received: 28 March 2013 - Revised: 19 July 2013 - Accepted: 5 August 2013 - Published: 29 October 2013

\begin{abstract}
The surface-drag and mass-transfer coefficients are determined within a self-consistent problem of waveinduced perturbations and mean fields of velocity and density in the air, using a quasi-linear model based on the Reynolds equations with down-gradient turbulence closure. Investigation of a harmonic wave propagating along the wind has disclosed that the surface drag is generally larger for shorter waves. This effect is more pronounced in the unstable and neutral stratification. The stable stratification suppresses turbulence, which leads to weakening of the momentum and mass transfer.
\end{abstract}

\section{Introduction}

Turbulent fluxes of momentum, sensible heat and latent heat at the sea surface characterize the energy and momentum transfer between the atmosphere and hydrosphere. These fluxes play an important role in many aspects of meteorological and oceanographic research, including climate modeling, weather forecasting, modeling of boundary-layer processes, etc. Turbulent exchange of energy and momentum between the ocean surfaces and the atmosphere to a large extent controls the energy and water cycle and general circulation of the ocean and the atmosphere. At the boundary layer scale, the fluxes in question control generation of waves and development of the upper ocean mixed layer. In numerical weather prediction and climate modeling, the air-sea fluxes are parameterized through mean flow meteorological parameters.
Turbulent fluxes of momentum $\tau=\rho_{\mathrm{a}} u_{*}^{2}$, sensible heat $H=\rho_{\mathrm{a}} C_{p} T_{*} u_{*}$ and latent heat $\Lambda=\rho_{\mathrm{a}} l q_{*} u_{*}$ (where $\rho_{\mathrm{a}}$ is air density, $u_{*}$ is friction velocity, $C_{p}$ is air heat capacity, $T_{*}$ and $q_{*}$ are constants respectively characterizing the fluxes of heat and moisture in the air, and $l$ is specific heat of evaporation) are expressed via bulk formulas through the following meteorological parameters measured at a reference level (usually $h_{10}=10 \mathrm{~m}$ above the water surface): wind speed $U_{10}$, temperature difference $\Delta T_{10}=T_{10}-T_{0}$, and relative humidity difference $\Delta q_{10}=q_{10}-q_{0}$.

$$
\begin{aligned}
\tau & =\rho_{\mathrm{a}} C_{D} U_{10}^{2}, \\
H & =\rho_{\mathrm{a}} C_{p} C_{H} U_{10} \Delta T_{10}, \text { and } \\
\Lambda & =\rho_{\mathrm{a}} l C_{l} U_{10} \Delta q_{10} .
\end{aligned}
$$

The resistance and heat/mass transfer coefficients $C_{D}$ (drag coefficient), $C_{H}$ (Stanton number), and $C_{l}$ (Dalton number) generally depend on the state of the water surface. For stationary and homogeneous processes in the atmosphere, these fluxes do not depend on the vertical coordinate within the lower $10 \%$ of the atmospheric boundary layer over water. This few dozen meter layer is thereafter referred as MABL (marine atmospheric boundary layer). As mentioned by Monin and Yaglom (1992), perturbations of moisture, usually unimportant in airflows above land, can be substantial above the sea surface (see also Zilitinkevich, 1976). The heat and moisture transfer coefficients are usually considered equal (see, e.g., Fairall et al., 2003). This makes it possible to describe the effects of stratification in MABL using one equation for the air density accounting for contributions from 
both heat and moisture. Then the mass flux becomes

$P=\rho_{*} u_{*}=C_{\rho} U_{10} \Delta \rho_{10}$,

where $\rho_{*}$ is the turbulent scale of density characterizing the mass flux.

One of important but still insufficiently explored questions is how the mass transfer coefficient $C_{\rho}$ depends on the wind speed. Experiments in the field (Fairall et al., 2003) and laboratory (Ocampo-Torres et al., 1994) have revealed generally weaker wind speed dependence for $C_{\rho}$ than for $C_{D}$. The COARE 3.0 algorithm (Fairall et al., 2003) states a weak increase of $C_{\rho}$ with the wind speed. A similar result is obtained by Brut et al. (2005). At the same time, data of Drennan et al. (2007) show no dependence at all. Detailed analyses of earlier investigations of $C_{D}$ are given, e.g., by Smith et al. (1996) and Weil et al. (2003).

The problem of exchange coefficients in MABL is closely related to the influence of surface waves on the air-sea momentum and mass transfer. In the presence of surface waves, the fluxes of momentum and mass consist of two parts: (i) the turbulent parts $\rho_{\mathrm{a}}\left\langle u^{\prime} w^{\prime}\right\rangle$ and $\left\langle\rho^{\prime} w^{\prime}\right\rangle$ (where $\rho^{\prime}$ is the density fluctuation, and $u^{\prime}$ and $w^{\prime}$ are horizontal and vertical velocity fluctuations, respectively), and (ii) the parts $\tau_{\text {wave }}$ and $P_{\text {wave }}$ caused by the wave-induced perturbations in the air.

$$
\begin{aligned}
\left\langle u^{\prime} w^{\prime}\right\rangle(\eta)+\tau_{\text {wave }}(\eta) & =u_{*}^{2}, \text { and } \\
\left\langle\rho^{\prime} w^{\prime}\right\rangle(\eta)+P_{\text {wave }}(\eta) & =\rho_{*} u_{*}
\end{aligned}
$$

(see, e.g., Janssen (1989, 1997), Makin et al. (1995), Makin and Mastenbroek (1996), Makin and Kudryavtsev (1999), and references therein).

We employ the commonly used turbulent flux model, based on the down-gradient approximation and turbulent exchange coefficients for momentum $K_{\mathrm{m}}$ (eddy viscosity) and mass $K_{\rho}$ (eddy conductivity):

$\left\langle u^{\prime} w^{\prime}\right\rangle=K_{\mathrm{m}} \frac{\mathrm{d} U}{\mathrm{~d} z},\left\langle\rho^{\prime} w^{\prime}\right\rangle=K_{\rho} \frac{\mathrm{d} \rho}{\mathrm{d} z}$.

The effect of wave-induced perturbations on the momentum transfer in MABL has been investigated in numerous theoretical (e.g., Janssen, 1989; Makin et al., 1995; Reutov and Troitskaya, 1996; Jenkins, 1992), numerical (e.g., Sullivan et al., 2000, 2008; Yang and Shen, 2010; Druzhinin et al., 2012) and experimental (e.g., Hsu et al., 1981; Hsu and Hsu, 1983; Troitskaya et al., 2011) studies. For the wind waves, decreasing turbulent flux of momentum near the water surface causes decreasing wind speed at the reference level (the wind waves decelerate wind due to the wind-to-wave momentum flux) and, as follows from Eq. (1), increasing the drag coefficient. Alternatively, field experiments show that swell can accelerate airflow due to delivery of momentum from wave to wind (see, e.g., Semedo et al. (2009) and references therein).

The wave-induced mechanism of the mass transfer is usually neglected, so that the mass flux is fully attributed to the turbulent transfer (see, e.g., Makin and Mastenbroek, 1996; Makin and Kudryavtsev, 1999). Janssen (1997) has analyzed wave-induced perturbations in airflow and concluded that their impact dramatically depends on the nature of the above perturbations.

In this paper we report how we develop a new theoretical model accounting for the wave-induced perturbations in airflow calculated within the Reynolds equations using the first order turbulence closure. The model generalizes our prior model (Reutov and Troitskaya, 1996; Troitskaya and Rybushkina, 2008) for the non-stratified atmosphere, validated through laboratory experiments (Troitskaya et al., 2011) and direct numerical simulation (Druzhinin et al., 2012) to the stratified atmosphere

The report consists of two parts. In Part 1 (this paper), we consider an idealized case of harmonic wave propagating along the wind - similarly to Reutov and Troitskaya (1996) but for the stratified airflow. We determine dimensionless parameters governing wind-wave interactions in the stratified MABL and investigate the air-sea momentum and heat transfer as dependent on these parameters. Of special interest is the case of swell, when the MABL stratification strongly affects wave-induced fluxes. In Part 2 (Troitskaya et al., 2013), we investigate how the calculated exchange coefficients depend on the wind-wave spectrum, and compare results with data collected in the COARE 3.0 algorithm (Fairall et al., 2003).

Part 1 is organized as follows. Basic definitions and scales are given in Sect. 2. Derivation and preliminary analyses of model equations are given in Sect. 3. In Sect. 4 we present results from calculation of the effects of individual harmonic waves on the airflow and stratification in MABL. In particular, we consider the effect of swell on the stratified MABL. Since we employ a quasi-linear model of the wind-wave interaction, the effect of total wave spectrum is represented as a superposition of contributions from individual harmonics. This analysis is given in Part 2.

\section{Basic definitions and MABL model}

In further analyses we employ the Monin-Obukhov similarity theory (MOST). It is based on the idea that local properties of turbulence in the atmospheric surface later are fully characterized by the normalized vertical turbulent flux of momentum $\tau / \rho_{\mathrm{a}}$ [or friction velocity $u_{*}=\sqrt{\tau / \rho_{\mathrm{a}}}$ ] and the buoyancy flux $b=-\frac{g}{\rho_{\mathrm{a}}}\left\langle\rho^{\prime} w^{\prime}\right\rangle$ determining the Obukhov length scale:

$$
L=\frac{u_{*}^{3}}{\kappa \frac{g}{\rho_{\mathrm{a}}}\left\langle\rho^{\prime} w^{\prime}\right\rangle},
$$

where $\rho_{\mathrm{a}}$ is reference value of air density, $L>0$ in stable stratification, and $L<0$ in unstable stratification (see, e.g., Monin and Yaglom, 1992). Besides L, MOST employs 
turbulent velocity and density scales:

$V=u_{*}, \rho_{*}=\frac{\left\langle\rho^{\prime} w^{\prime}\right\rangle}{u_{*}}$.

In particular, MOST states that dimensionless velocity and density gradients in the surface layer are expressed through universal functions of the dimensionless height $\zeta=\frac{z}{L}$ :

$\frac{\kappa z}{u_{*}} \frac{\mathrm{d} u}{\mathrm{~d} z}=\Phi_{\mathrm{m}}\left(\frac{z}{L}\right), \frac{1}{P r_{\mathrm{t}}} \frac{\kappa z}{\rho_{*}} \frac{\mathrm{d} \rho}{\mathrm{d} z}=\Phi_{\rho}\left(\frac{z}{L}\right)$,

where $\kappa$ is the von Kármán constant $(\kappa \approx 0.4), P r_{\mathrm{t}}=K_{\mathrm{m}} / K_{\rho}$ is the turbulent Prandtl number (in the surface later $P r_{\mathrm{t}} \approx$ $0.8), K_{\mathrm{m}}$ and $K_{\rho}$ are turbulent exchange coefficients for momentum and buoyancy.

Of the various empirical approximations of the functions $\Phi_{\mathrm{m}}(\zeta)$ and $\Phi_{\rho}(\zeta)$ (e.g., Fairall et al., 2003; Liu et al., 1979; Businger et al., 1971; Zeng et al., 1998), we select those from Zeng et al. (1998) used in the algorithms COARE 2.5 and COARE 3.0:

$\Phi_{m}(\zeta)=\left\{\begin{array}{lll}0.7 \kappa^{2 / 3}(-\zeta)^{1 / 3} & \text { for } \zeta<\zeta_{m}=-1.574 & \text {-strong unstable stratification } \\ (1-16 \zeta)^{-1 / 4} & \text { for } \zeta_{m}<\zeta<0 & \text { - unstable stratification, } \\ 1+5 \zeta & \text { for } 0<\zeta<1 & \text { - stable stratification, } \\ 5+\zeta & \text { for } \zeta>1 & \text { - strong stable stratification. }\end{array}\right.$

$\Phi_{\rho}(\zeta)=\left\{\begin{array}{lll}0.9 \kappa^{4 / 3}(-\zeta)^{-1 / 3} & \text { for } \zeta<\zeta \rho=-0.465 & \text {-strong unstable stratification } \\ (1-16 \zeta)^{-1 / 2} & \text { for } \zeta \rho \zeta<0 & \text { - unstable stratification, } \\ 1+5 \zeta & \text { for } 0<\zeta<1 & \text { - stable stratification, } \\ 5+\zeta & \text { for } \zeta>1 & \text {-strong stable stratification. }\end{array}\right.$

Zeng et al. (1998) used $P r_{\mathrm{t}}=1$, but Eqs. (11) and (12) do not depend on this assumption. We then combine Eq. (10) with the familiar down-gradient transport formulation:

$K_{\mathrm{m}} \frac{\mathrm{d} u}{\mathrm{~d} z}=u_{*}^{2}, K_{\rho} \frac{\mathrm{d} \rho}{\mathrm{d} z}=\left\langle\rho^{\prime} w^{\prime}\right\rangle=\rho_{*} u_{*}$,

which yields

$K_{\mathrm{m}}=\frac{u_{*} \kappa z}{\Phi_{\mathrm{m}}(z / L)}, K_{\rho}=\frac{1}{P r_{\mathrm{t}}} \frac{u_{*} \kappa z}{\Phi_{\rho}(z / L)}$.

At $z \ll L$, Eqs. (10) and (11) yield $\Phi_{\mathrm{m}}(\zeta)=\Phi_{\rho}(\zeta)=1$; Eq. (14) yields

$K_{\mathrm{m}}(\zeta)=\kappa z u_{*}, \quad K_{\rho}(\zeta)=\frac{1}{P r_{\mathrm{t}}} \kappa z u_{*} ;$

and Eqs. (13) and (15) yield logarithmic velocity and density profiles:

$u(z)=\frac{u_{*}}{\kappa} \ln \frac{z}{z_{0}}$,

$\rho(z)-\rho(0)=\frac{\rho_{*}}{\kappa} \operatorname{Pr}_{\mathrm{t}} \ln \frac{z}{z_{0 \rho}}=\frac{\left\langle\rho^{\prime} w^{\prime}\right\rangle}{\kappa u_{*}} \operatorname{Pr}_{\mathrm{t}} \ln \frac{z}{z_{0 \rho}}$,

where $z_{0}$ and $z_{0 \rho}$ are roughness parameters.
Combining Eqs. (13) and (14) and integrating over $z$ yield the following mean wind and density profiles in the atmospheric surface layer:

$u(z)=\frac{u_{*}}{\kappa}\left(\ln \frac{z}{z_{0}}+\Psi_{\mathrm{m}}\left(\frac{z}{L}\right)\right)$,

$\rho(z)-\rho(0)=\frac{\left\langle\rho^{\prime} w^{\prime}\right\rangle}{\kappa u_{*}} \operatorname{Pr}_{\mathrm{t}}\left(\ln \frac{z}{z_{0 \rho}}+\Psi_{\rho}\left(\frac{z}{L}\right)\right)$,

where the right-hand sides consist of two parts: one controlled by the surface roughness length, and the another controlled by the Obukhov length $L$ (Fairall et al., 2003; Zeng et al., 1998).

Taking into account Eqs. (18) and (19), the resistance and mass transfer coefficients, Eqs. (1) and (4), become

$$
\begin{aligned}
C_{\mathrm{D} 10} & =\frac{u_{*}^{2}}{U_{10}^{2}}=\frac{\kappa^{2}}{\left(\ln \frac{h_{10}}{z_{0}}+\Psi_{\mathrm{m}}\left(\zeta_{10}\right)\right)^{2}}, \\
C_{\rho 10} & =\frac{\rho_{*} u_{*}}{U_{10} \Delta \rho_{10}} \\
& =\frac{\kappa^{2}}{\operatorname{Pr}_{\mathrm{t}}\left(\ln \frac{h_{10}}{z_{0}}+\Psi_{\mathrm{m}}\left(\zeta_{10}\right)\right)\left(\ln \frac{h_{10}}{z_{0 \rho}}+\Psi_{\rho}\left(\zeta_{10}\right)\right)},
\end{aligned}
$$

where $h_{10}=10 \mathrm{~m}$ is the reference level, and $\zeta_{10}=h_{10} / L$.

In neutral stratification, $L \rightarrow \infty$ and $\Psi_{\mathrm{m}}, \Psi_{\rho} \rightarrow 0$. Then the resistance and mass transfer coefficients are fully determined by the surface roughness lengths:

$$
\begin{aligned}
C_{\mathrm{D} 10 \mathrm{~N}} & =\frac{\kappa^{2}}{\left(\ln \left(h_{10} / z_{0}\right)\right)^{2}}, \\
C_{\rho 10 \mathrm{~N}} & =\frac{\kappa^{2}}{\operatorname{Pr}_{\mathrm{t}} \ln \left(h_{10} / z_{0}\right) \ln \left(h_{10} / z_{0 \rho}\right)} \\
& =\frac{\kappa \sqrt{C_{\mathrm{D} 10 \mathrm{~N}}}}{\operatorname{Pr}_{\mathrm{t}} \ln \left(h_{10} / z_{0 \rho}\right)} .
\end{aligned}
$$

The momentum transfer in MABL close to the surface is determined by the surface waves and viscous friction. In the presence of waves, conservation of the momentum flux with height yields

$$
K_{\text {mwave }} \frac{\mathrm{d} u}{\mathrm{~d} z}+\tau_{\text {wave }}(z)=u_{*}^{2} .
$$

Here, $\tau_{\text {wave }}(z)$ is the flux from wind to waves decaying with distance from the water surface, and $K_{\text {mwave }}(z)$ is the eddy viscosity. In the presence of waves, $K_{\text {mwave }}(z)$ may differ from the eddy viscosity in the airflow over smooth surface.

Reutov and Troitskaya (1996) and Troitskaya et al. (2011) have demonstrated that the water surface can be locally treated as aerodynamically smooth, which yields the following asymptotic solution to Eq. (24) at $z \ll L$ :

$u(z)=\frac{u_{*}}{\kappa} \ln \frac{z}{z_{00}}-\Delta u$, 
where $z_{00}=0.11 v_{\mathrm{a}} / u_{*}, v_{\mathrm{a}}$ is molecular viscosity of the air, and

$\Delta u=\int_{0}^{\infty} \frac{\tau_{\text {wave }}(z)}{K_{\text {mwave }}(z)} \mathrm{d} z+\int_{0}^{\infty} \frac{u_{*}^{2}\left(K_{\text {mwave }}(z)-K_{\mathrm{m}}(z)\right)}{K_{\mathrm{m}}(z) K_{\text {mwave }}(z)} \mathrm{d} z$,

where $\tau_{\text {wave }}(z)$ is specified by the wave spectrum.

Then the roughness parameter $z_{0}$ in Eq. (22) becomes

$z_{0}=z_{00} \exp \left(\frac{\kappa \Delta u}{u_{*}}\right)$,

and the drag coefficient becomes

$C_{\mathrm{D} 10 \mathrm{~N}}=\frac{\kappa^{2}}{\left(\ln \left(\frac{h_{10} u_{*}}{0.11 v_{\mathrm{a}}}\right)-\frac{\kappa \Delta u}{u_{*}}\right)^{2}}$.

It has been demonstrated in many experiments (see, e.g., Garratt, 1977, and references therein) that the drag coefficient $C_{\mathrm{D} 10 \mathrm{~N}}$ increases with increasing $u_{*}$. As follows from Eq. (28), this implies that roughness parameter $z_{0}$ and then $\Delta u$ also strongly increase with increasing $u_{*}$. This effect can be parameterized, in particular, using Charnock's formula for $z_{0}$, which yields

$C_{\mathrm{D} 10 \mathrm{~N}}=\frac{\kappa^{2}}{\left(\ln \left(h_{10} g / m u_{*}^{2}\right)\right)^{2}}$,

where $m$ is the Charnock constant.

Similar analysis applied to the turbulent flux of mass yields the expression for $z_{0 \rho}$ similar to Eq. (27):

$z_{0 \rho}=z_{00 \rho} \exp \left(\frac{\kappa \Delta \rho}{P r_{\mathrm{t}} \rho_{*}}\right)$,

where

$\Delta \rho=\int_{0}^{\infty} \frac{\tau_{\rho \text { wave }}(z)}{K_{\rho \text { wave }}(z)} \mathrm{d} z+\int_{0}^{\infty} \frac{\rho_{*} u_{*}\left(K_{\rho \text { wave }}(z)-K_{\rho}(z)\right)}{K_{\rho}(z) K_{\rho \text { wave }}(z)} \mathrm{d} z ;$

$\tau_{\rho \text { wave }}(z)$ is the wave mass flux and $K_{\rho \text { wave }}(z)$ is the turbulent mass transfer coefficient in MABL in the presence of waves. According to Liu et al. (1979), $z_{00 \rho}=\alpha v_{\mathrm{a}} / u_{*} ; \alpha$ is the dimensionless coefficient of order unity dependent on the type of stratification - in temperature or in humidity. Eq. (23) then yields

$C_{\rho 10 \mathrm{~N}}=\frac{\kappa \sqrt{C_{\mathrm{D} 10 \mathrm{~N}}}}{\operatorname{Pr}_{\mathrm{t}}\left(\ln \left(\frac{h_{10} u_{*}}{\alpha \nu_{\mathrm{a}}}\right)-\frac{\kappa \Delta \rho}{P r_{\mathrm{t}} \rho_{*}}\right)}$.

Prior results (e.g., Janssen and Komen, 1985) and our estimates presented in Sect. 4 show that the wave mass flux is small. This means that $\Delta \rho$ can only be affected by the impact of waves on the eddy conductivity. A number of theoretical models (see Makin and Mastenbroek, 1996) suggest that surface waves decrease the eddy conductivity. If so,
$K_{\rho \text { wave }}(z)-K_{\rho}(z)<0$, and $\Delta \rho<0$ grows in absolute value with increasing wind speed. In other models (see Reutov and Troitskaya, 1996), eddy conductivity does not depend on waves, meaning $\Delta \rho=0$. In both cases the denominator in Eq. (32) is an increasing function of the wind speed. The drag coefficient $C_{\mathrm{D} 10 \mathrm{~N}}$ in the numerator also increases with increasing $U_{10}$. These counter-effects explain quite weak dependence of $C_{\rho 10 \mathrm{~N}}$ on the wind speed. Experimental evidence of such dependence is rather uncertain. Some authors assume that $C_{\rho 10 \mathrm{~N}}$ weakly grows with increasing wind speed (Ocampo-Torres et al., 1994; Brut et al., 2005); others do not find any pronounced dependence (Drennan et al., 2007). In this paper we attempt to elucidate this open question with the aid of a quasi-linear model of air-sea interaction generalizing our earlier model (Reutov and Troitskaya, 1996; Troitskaya and Rybushkina, 2008).

\section{Basic equations of quasi-linear model of MABL above wavy water surface}

The model is based on the Reynolds equations for stratified fluid in Boussinesq approximation:

$$
\begin{aligned}
& \frac{\partial\left\langle u_{i}\right\rangle}{\partial t}+\left\langle u_{j}\right\rangle \frac{\partial\left\langle u_{i}\right\rangle}{\partial x_{j}}+\frac{1}{\rho_{\mathrm{a} 0}} \frac{\partial\langle p\rangle}{\partial x_{j}}-\frac{\langle\rho\rangle}{\rho_{\mathrm{a} 0}} g \delta_{i 3}=\frac{\partial \sigma_{i j}}{\partial x_{j}}, \\
& \frac{\partial\langle\rho\rangle}{\partial t}+\left\langle u_{j}\right\rangle \frac{\partial\langle\rho\rangle}{\partial x_{j}}=\frac{\partial\left\langle u_{j}^{\prime} \rho^{\prime}\right\rangle}{\partial x_{j}}, \\
& \operatorname{div}\langle\boldsymbol{u}\rangle=0,
\end{aligned}
$$

closured using the down-gradient approximation written as

$$
\sigma_{i j}=K_{\mathrm{m}}\left(\frac{\partial\left\langle u_{i}\right\rangle}{\partial x_{j}}+\frac{\partial\left\langle u_{j}\right\rangle}{\partial x_{i}}\right),
$$

$\left\langle u_{j}^{\prime} \rho^{\prime}\right\rangle=K_{\rho} \frac{\partial\langle\rho\rangle}{\partial x_{j}}$,

where $\rho=\rho_{\mathrm{a}}-\rho_{\mathrm{a} 0}$.

At the water surface, the velocity components satisfy the two classical boundary conditions, i.e., kinematic boundary condition:

$\frac{\partial \xi}{\partial t}+\left.\left\langle u_{i}\right\rangle \frac{\partial \xi}{\partial x_{i}}\right|_{z=\xi}=\left.\left\langle u_{3}\right\rangle\right|_{z=\xi}, \quad i=1,2$,

and non-slipping boundary condition:

$\left\langle u_{i}^{\mathrm{a}}\right\rangle+\left.\left\langle u_{3}^{\mathrm{a}}\right\rangle \frac{\partial \xi}{\partial x_{i}}\right|_{z=\xi}=\left\langle u_{i}^{\mathrm{w}}\right\rangle+\left.\left\langle u_{3}^{\mathrm{w}}\right\rangle \frac{\partial \xi}{\partial x_{i}}\right|_{z=\xi}, \quad i=1,2$,

where $\left\langle u_{i}^{\mathrm{a}}\right\rangle,\left\langle u_{i}^{\mathrm{w}}\right\rangle$ are Cartesian projections of the velocity in air and water, $\xi$ is the elevation of the water surface.

The boundary conditions for density follow from the requirement of equality of the air and water temperatures. Accounting for 1000 times difference between the air and water 
heat capacity, the air temperature (and density) at the surface can be treated as constant:

$$
\left.\langle\rho\rangle\right|_{z=\xi}=0 .
$$

Similarly to Reutov and Troitskaya (1996), we start with considering a single harmonic surface wave with the amplitude $a$ and the wave number $k$, assuming that $\boldsymbol{k}$ is parallel to the wind direction. To avoid geometric nonlinearity, we introduce curvilinear reference frame following the wave:

$x=\xi-a e^{-k \eta} \sin k \xi$,

$z=\eta+a e^{-k \eta} \cos k \xi$.

Jacobian of this transformation is

$J=\frac{\partial(x, y)}{\partial(\xi, \eta)}=1-2 \mathrm{ka} e^{-k \eta} \cos k \xi+(\mathrm{ka})^{2} e^{-2 k \eta}$.

Since two-dimensional flow is considered, we employ the stream function $\psi$ :

$\left\langle u_{x}\right\rangle=\frac{\partial \psi}{\partial z},\left\langle u_{z}\right\rangle=-\frac{\partial \psi}{\partial x}$.

Then the system of Reynolds equations can be rewritten in terms of the stream function $\psi$ and vorticity $\chi$ :

$$
\begin{aligned}
& \frac{\partial \chi}{\partial t}+\frac{\partial(\chi, \psi)}{\partial(x, z)}-\frac{g}{\rho_{\mathrm{a} 0}} \frac{\partial\langle\rho\rangle}{\partial x}=\frac{\partial^{2} \sigma_{x x}}{\partial x \partial z}+\frac{\partial^{2} \sigma_{x z}}{\partial z^{2}}-\frac{\partial^{2} \sigma_{z z}}{\partial x \partial z} \\
& \quad-\frac{\partial^{2} \sigma_{x z}}{\partial x^{2}}, \\
& \chi=\frac{\partial^{2} \psi}{\partial x^{2}}+\frac{\partial^{2} \psi}{\partial z^{2}}, \\
& \frac{\partial\langle\rho\rangle}{\partial t}+\frac{\partial(\langle\rho\rangle, \psi)}{\partial(x, z)}=\frac{\partial}{\partial x}\left(K_{\rho} \frac{\partial\langle\rho\rangle}{\partial x}\right)+\frac{\partial}{\partial z}\left(K_{\rho} \frac{\partial\langle\rho\rangle}{\partial z}\right) .
\end{aligned}
$$

Assuming that the turbulent exchange coefficients depend only on the curvilinear coordinate $\eta$, the system Eqs. (45)(47) in curvilinear coordinates Eqs. (41)-(42) become

$$
\begin{gathered}
J^{2}\left(\frac{\partial(\chi, \psi)}{\partial(\xi, \eta)}-\frac{g}{\rho_{\mathrm{a} 0}}\left(\frac{\partial\langle\rho\rangle}{\partial \xi} \frac{\partial x}{\partial \xi}+\frac{\partial\langle\rho\rangle}{\partial \eta} \frac{\partial x}{\partial \eta}\right)\right) \\
=J^{2}\left(\frac{\partial^{2}}{\partial \xi^{2}}+\frac{\partial^{2}}{\partial \eta^{2}}\right)\left(K_{\mathrm{m}} \chi\right)-2 J K_{\mathrm{m} \eta \eta} \psi_{\xi \xi} \\
\quad+J_{\eta} K_{\mathrm{m} \eta}\left(\psi_{\xi \xi}-\psi_{\eta \eta}\right)-K_{\mathrm{m} \eta \eta}\left(\psi_{\xi} J_{\xi}+\psi_{\eta} J_{\eta}\right) \\
\quad+2 J_{\xi}\left(-K_{\mathrm{m} \eta} \psi_{\xi \eta}+K_{\mathrm{m} \eta \eta} \psi_{\xi}\right)+\frac{J_{\eta}^{2}}{J} K_{\mathrm{m} \eta} \psi_{\eta} \\
\chi=\frac{1}{J}\left(\frac{\partial^{2} \psi}{\partial \xi^{2}}+\frac{\partial^{2} \psi}{\partial \eta^{2}}\right), \\
\frac{\partial(\langle\rho\rangle, \psi)}{\partial(\xi, \eta)}=\frac{\partial}{\partial \xi}\left(K_{\rho} \frac{\partial\langle\rho\rangle}{\partial \xi}\right)+\frac{\partial}{\partial \eta}\left(K_{\rho} \frac{\partial\langle\rho\rangle}{\partial \eta}\right) ;
\end{gathered}
$$

and the boundary conditions Eqs. (38)-(40) become

$$
\begin{aligned}
& \left.\frac{\partial \psi}{\partial \xi}\right|_{\eta=0}=0,\left.\quad \frac{\partial \psi}{\partial \eta}\right|_{\eta=0}=-c+2 \operatorname{ckaRe}\left(e^{i k \xi}\right), \\
& \left.\langle\rho\rangle\right|_{\eta=0}=0 .
\end{aligned}
$$

At $\eta \rightarrow \infty$, wave-induced perturbations decay and momentum and buoyancy fluxes are conserved.

Following Jenkins (1992), we consider nonlinear Eqs. (48)-(50) using quasi-linear model. The higher harmonics of perturbations are neglected, and the main harmonic is defined with the accuracy to terms of order $(\mathrm{ka})$, and average fields with accuracy to terms of order $(\mathrm{ka})^{2}$. In other words, considering the equation for perturbations, we keep terms of order $(\mathrm{ka})^{3}$ if these are due to the average wave-induced fields, and neglect them if they are due to nonlinear interaction between 1 st and 2nd harmonics. This approach is applicable for small Reynolds numbers (see Batchelor, 1967). In the turbulent regime of the flow, the Reynolds number as defined by the molecular viscosity is huge, but the average flow dynamics described within the Reynolds equations is determined by the effective Reynolds number, which is defined by the eddy viscosity coefficient. The effective Reynolds number for the wave disturbances induced in the airflow $R e_{\text {eff }}$ was estimated by Troitskaya et al. (2011) as a value of order (ka). The estimation assumes that the velocity scale $u_{\text {wave }}$ is of order cka, the length scale is the distance from the surface, and the viscosity coefficient is $v_{\text {turb }}=\kappa u_{*} z$. Taking into account that the vertical scale of the turbulent boundary layer for the wave disturbances is $\delta=u_{*} /$ (ck) (see Troitskaya and Rybushkina, 2008), this yields $R e_{\text {eff }}=\delta k u_{\text {wave }} z / v_{\text {turb }} \sim \mathrm{ka}<1$. Now the wave-induced disturbances can be described within the linear approximation due to the small effective Reynolds number.

Troitskaya et al. (2010a, b, 2011) have demonstrated applicability of the quasi-linear theory of wind-wave interaction through laboratory experiments with particle image velocimetry (PIV) technique, even for quite steep waves $(\mathrm{ka}=0.3)$. Applicability was also confirmed by Druzhinin et al. (2012) in direct numerical simulation of a turbulent boundary layer above waves with the steepness up to $(\mathrm{ka})=0.2$.

We search for a solution to Eqs. (48)-(50) in the form

$$
\begin{gathered}
\chi=\chi_{0}(\eta)+\operatorname{Re}\left(\chi_{1}(\eta) e^{i k \xi}\right), \\
\psi=\psi_{0}(\eta)+\operatorname{Re}\left(\psi_{1}(\eta) e^{i k \xi}\right), \\
\langle\rho\rangle=\rho_{0}(\eta)+\operatorname{Re}\left(\rho_{1}(\eta) e^{i k \xi}\right),
\end{gathered}
$$

which yields the following equations for the 1st harmonic:

$$
\begin{aligned}
& i k\left(\psi_{0 \eta} \chi_{1}-\psi_{1} \chi_{0 \eta}\right)-i k \frac{g}{\rho_{\mathrm{a} 0}} \rho_{1}+i \mathrm{ka} \frac{g}{\rho_{\mathrm{a} 0}} \frac{\mathrm{d} \rho_{0}}{\mathrm{~d} \eta} e^{-k \eta} \\
& =\frac{\mathrm{d}^{2}}{\mathrm{~d} \eta^{2}}\left(K_{\mathrm{m}} \chi_{1}\right)-k^{2} K_{\mathrm{m}} \chi_{1}+2 \psi_{1} k^{2} K_{\mathrm{m} \eta \eta} \\
& -2 k^{2} a e^{-k \eta}\left(K_{\mathrm{m} \eta} \psi_{0 \eta}\right)_{\eta} \\
& \psi_{1 \eta \eta}-k^{2} \psi_{1}=\chi_{1}-2 \mathrm{ka} e^{-k \eta} \chi_{0},
\end{aligned}
$$


$i k\left(\psi_{0 \eta} \rho_{1}-\psi_{1} \rho_{0 \eta}\right)=\frac{\mathrm{d}}{\mathrm{d} \eta}\left(K_{\rho} \frac{\mathrm{d} \rho_{1}}{\mathrm{~d} \eta}\right)-k^{2} K_{\rho} \rho_{1} ;$

and for the mean flow, the equations

$$
\begin{aligned}
& \frac{\mathrm{d}}{\mathrm{d} \eta}\left(K_{\mathrm{m}} \chi_{0}\right)=-\frac{\mathrm{d} T}{\mathrm{~d} \eta} \\
& -\frac{\mathrm{d} T}{\mathrm{~d} \eta}=k K_{\mathrm{m} \eta}\left[\mathrm{ka} \frac{\mathrm{d}}{\mathrm{d} \eta} \operatorname{Re}\left(\psi_{1} e^{-k \eta}\right)+2(\mathrm{ka})^{2} e^{-2 k \eta} \psi_{0 \eta}\right] \\
& \quad-\frac{1}{2} k \operatorname{Im}\left(\psi_{1}^{*} \chi_{1}\right)+\frac{1}{2} \frac{g}{\rho_{\mathrm{a} 0}} \mathrm{kaIm}\left(\rho_{1} e^{-k \eta}\right) \\
& \frac{\mathrm{d}^{2} \psi_{0}}{\mathrm{~d} \eta^{2}}=\chi_{0}\left(1+(\mathrm{ka})^{2} e^{-2 k \eta}\right)-\mathrm{ka} e^{-k \eta} \operatorname{Re} \chi_{1}, \\
& K_{\rho} \frac{\mathrm{d} \rho_{0}}{\mathrm{~d} \eta}=\rho_{*} u_{*}-\frac{k}{2} \operatorname{Im}\left(\rho_{1} \psi_{1}^{*}\right) .
\end{aligned}
$$

In Eq. (61), the vertical turbulent flux of mass tends to $\rho_{*} u_{*}$ at $\eta \rightarrow \infty$.

As follows from conservation of the vertical turbulent flux of momentum within MABL, the boundary condition for Eq. (58) is $\left.K_{\mathrm{m}} \chi_{0}\right|_{\eta \rightarrow \infty}=u_{*}^{2}$. In Eq. (58), $T(\eta)=\tau_{\text {wave }}$ is the wave-induced component of the momentum flux satisfying the condition $T(\eta) \rightarrow 0$ at $\eta \rightarrow \infty$. Integrating Eq. (58) yields

$K_{\mathrm{m}}(\eta) \chi_{0}+T(\eta)=u_{*}^{2}$.

Similarly, it can be concluded from Eq. (61) that $\frac{k}{2} \operatorname{Im}\left(\rho_{1} \psi_{1}^{*}\right)$ is the wave-induced part of the turbulent mass flux.

The non-slip boundary condition for the mean velocity reads

$$
\left.\frac{\partial \psi}{\partial \eta}\right|_{\eta=0}=-c .
$$

The boundary conditions for harmonic waves follow from Eq. (51):

$\left.\psi_{1}\right|_{\eta=0}=0,\left.\quad \frac{\partial \psi_{1}}{\partial \eta}\right|_{\eta=0}=2 \mathrm{cka},\left.\quad \rho_{1}\right|_{\eta=0}=0$.

Equations (55)-(61) with boundary conditions (63) and (64) determine velocity and density profiles in MABL above propagating harmonic wave. For the numerical solution, it is convenient to use the following dimensionless variables:

dimensionless vertical coordinate $Y=\frac{\eta u_{*}}{v}=\frac{\eta}{z_{v}}$,

dimensionless horizontal coordinate $\varsigma=k \xi$, dimensionless vorticity $X=\frac{v_{a} \chi}{u_{*}^{2}}$,

dimensionless density $R=\frac{\rho_{1}}{\rho_{*}}$,

dimensionless stream function $\Psi=\frac{\psi}{v_{\mathrm{a}}}$, and

dimensionless turbulent exchange transfer coefficients

$N_{0}=\frac{K_{\mathrm{m}}}{v_{\mathrm{a}}}$ and $N_{\mathrm{R} 0}=\frac{K_{\rho}}{v_{\mathrm{a}}}$.
We search for the solution in the form

$$
\left\{\begin{array}{l}
X=X_{0}(Y)+\operatorname{Re}\left(X_{1}(Y) e^{i \varsigma}\right), \\
\Psi=\Psi_{0}(Y)+\operatorname{Re}\left(\Psi_{1}(Y) e^{i \varsigma}\right), \\
R=R_{0}(Y)+\operatorname{Re}\left(R_{1}(Y) e^{i \varsigma}\right) .
\end{array}\right.
$$

This yields the following equations for the 1st harmonics:

$$
\begin{aligned}
i\left(\frac{\mathrm{d} \Psi_{0}}{\mathrm{~d} Y} X_{1}-\Psi_{1} \frac{\mathrm{d} X_{0}}{\mathrm{~d} Y}\right)-i R i R_{1}+i R i \frac{\mathrm{ka}}{\mathrm{kz}_{\nu}} \frac{\mathrm{d} R_{0}}{\mathrm{~d} Y} e^{-\mathrm{kz}_{v} Y} \\
=\frac{1}{\mathrm{kz}_{v}}\left(\frac{\mathrm{d}^{2}}{\mathrm{~d} Y^{2}}\left(N_{0} X_{1}\right)-\left(\mathrm{kz}_{v}\right)^{2} N_{0} X_{1}+2 \Psi_{1}\left(\mathrm{kz}_{v}\right)^{2} N_{0 Y Y}\right. \\
\left.\quad-2(\mathrm{ka})\left(\mathrm{kz}_{v}\right) e^{-\mathrm{kz}_{v} Y}\left(N_{0 Y} \Psi_{0 Y}\right)_{Y}\right),
\end{aligned}
$$

$\Psi_{1 Y Y}-\left(\mathrm{kz}_{v}\right)^{2} \Psi_{1}=X_{1}-2 \mathrm{ka}^{-\mathrm{kz}_{\nu} Y} X_{0}$,

$i\left(\Psi_{0 Y} R_{1}-\Psi_{1} R_{0 Y}\right)=\frac{1}{\mathrm{kz}_{v}}\left[\frac{\mathrm{d}}{\mathrm{d} Y}\left(N_{R 0} \frac{\mathrm{d} R_{1}}{\mathrm{~d} Y}\right)-\left(\mathrm{kz}_{v}\right)^{2} N_{R 0} R_{1}\right] ;$

and yields the equations for the mean velocity and density

$$
\begin{aligned}
\frac{\mathrm{d}}{\mathrm{d} Y}\left(N_{0} X_{0}\right) & =\mathrm{kz}_{v}\left[\mathrm{ka}_{0 Y} \operatorname{Re}\left(\Psi_{1 Y}-\mathrm{kz}_{v} \Psi_{1}\right) e^{-\mathrm{kz}_{\mathrm{v}} Y}\right. \\
& \left.+2(\mathrm{ka})^{2} e^{-2 \mathrm{kz}_{\mathrm{v}} Y} N_{0 Y} \Psi_{0 Y}\right] \\
& -\frac{1}{2}\left(\mathrm{kz}_{v}\right) \operatorname{Im}\left(\Psi_{1}^{*} X_{1}\right)+\frac{R i}{2}(\mathrm{ka}) \operatorname{Im}\left(R_{1} e^{-\mathrm{kz}_{\mathrm{v}} Y}\right) \\
& =-\frac{\mathrm{d} \tau_{\mathrm{wave}}}{\mathrm{d} Y}, \\
\frac{\mathrm{d}^{2} \Psi_{0}}{\mathrm{~d} Y^{2}} & =X_{0}\left(1+(\mathrm{ka})^{2} e^{-2 \mathrm{kz}_{v} Y}\right)-\mathrm{ka} e^{-\mathrm{kz}_{v} Y} \operatorname{Re} X_{1}, \\
N_{R_{0}} \frac{\mathrm{d} R_{0}}{\mathrm{~d} Y} & =1-\frac{\mathrm{kz}_{v}}{2} \operatorname{Im}\left(R_{1} \Psi_{1}^{*}\right),
\end{aligned}
$$

with the boundary conditions

$$
\begin{aligned}
\left.N_{0} X_{0}\right|_{Y \rightarrow \infty} & =1,\left.\quad \frac{\partial \Psi_{0}}{\partial Y}\right|_{Y=0}=-\frac{c}{u_{*}} . \\
\left.\Psi_{1}\right|_{Y=0}=0,\left.\quad \frac{\partial \Psi_{1}}{\partial Y}\right|_{Y=0} & =2 \frac{c}{u_{*}} \mathrm{ka},\left.\quad R_{1}\right|_{Y=0}=0 .
\end{aligned}
$$

Here the following dimensionless parameters appear: wave steepness $\mathrm{ka}$, dimensionless wave number $\mathrm{kz}_{\nu}$, Richardson number $R i=\frac{g \rho_{*} \nu_{\mathrm{a}}}{\rho_{\mathrm{a} 0} u_{*}^{3}}$, and wave age $c / u_{*}$. Additionally, the expression for $N_{R 0}$ includes the Prandtl number. Combinations $\mathrm{kz}_{v}=\frac{k v_{\mathrm{a}}}{u_{*}}$ and $R i=\frac{v_{\mathrm{a}}}{\kappa L u_{*}}$ are of order $10^{-3}$, which make the above scaling convenient for analyzing close vicinity of the air-sea interface.

We consider the ratio of the Obukhov length scale $L$ to the surface wave length $k^{-1}$. It follows from the dispersion 
relation that $k=g / c^{2}$. Then Eq. (8) for $L$, and Eq. (9) for the density scale $\rho_{*}$, yield

$$
L k=\frac{u_{*}^{2}}{c^{2} \frac{\rho_{*}}{\rho_{\mathrm{a}}}},
$$

so that $L k$ depends on the wave age $u_{*} / c$ (the basic air-sea interaction parameter; see, e.g., Plant, 1982). Hence, the momentum and heat transfers between waves and mean flow basically depend on $u_{*} / c$. In the next section we consider this dependence in case of stratified MABL interacting with harmonic surface wave.

\section{Interaction of stratified MABL with harmonic wave}

To solve Eqs. (66)-(71) with boundary conditions Eqs. (72) and (73), we employ eddy viscosity $K_{\mathrm{m}}$ and eddy conductivity $K_{\rho}$ determined in MABL by Eqs. (11), (12), and (14).

At $z \ll L$ (in the neutrally stratified MABL), these equations reduce to the set of equations in Eq. (15): $K_{\mathrm{m}}=$ $\operatorname{Pr}_{\mathrm{t}} K_{\rho}=\kappa z u_{*}$. Close to the surface, $K_{\mathrm{m}}$ behaves as

$K_{\mathrm{m}}=v_{\mathrm{a}} f\left(\eta_{*}\right)$,

where $\eta_{*}=\eta / z_{v}, z_{v}=v_{\mathrm{a}} / u_{*}$. In further analysis we adopt $f\left(\eta_{*}\right)$ obtained by Smol'yakov (1973) for turbulent flow over smooth plate:

$f\left(\eta_{*}\right)=1+\kappa \eta_{*}\left(1-\exp \left\{-\left(\frac{\eta_{*}}{l_{\mathrm{m}}}\right)^{2}\right\}\right)$,

where $l_{\mathrm{m}}=22.4$. Substituting $z$ for $\eta$, Eqs. (75) and (76) at $\eta_{*} \gg l_{\mathrm{m}}$ yield the set of equations in Eq. (15).

In the stratified MABL, we determine eddy viscosity, combining the asymptotes Eqs. (14) and (75):

$K_{\mathrm{m}}(\eta)=\frac{\nu_{\mathrm{a}} f\left(\eta / z_{\nu}\right)}{\Phi_{\mathrm{m}}(\eta / L)}$.

In the viscous sublayer above smooth plate, experimental data show that the velocity and temperature profiles are quite similar (Ocampo-Torres et al., 1994), and $K_{\rho}$ is expressed similarly to Eq. (77):

$K_{\rho}(\eta)=\frac{v_{\mathrm{a}} f_{\rho}\left(\eta / z_{v}\right)}{\Phi_{\rho}(\eta / L)}$.

where $f_{\rho}\left(\eta_{*}\right)$ is expressed similarly to Eq. (76):

$f_{\rho}\left(\eta_{*}\right)=v_{\mathrm{a}}\left(\frac{1}{P r}+\frac{\kappa \eta_{*}}{P r_{\mathrm{t}}}\left(1-\exp \left\{-\left(\frac{\eta_{*}}{l_{\rho}}\right)^{2}\right\}\right)\right)$.

Here, $\operatorname{Pr}=v_{\mathrm{a}} / v_{\rho}$ is the Prandtl number, i.e., the ratio of molecular viscosity to heat conductivity (in the air $P r=0.7$; see Monin and Yaglom, 1992); $P r_{\mathrm{t}}=K_{\mathrm{m}} / K_{\rho}$ is the turbulent Prandtl number for neutral and near-neutral stratification (in the air $P r_{\mathrm{t}}=K_{\mathrm{m}} / K_{\rho}=0.85$; see Monin and Yaglom, 1992), and $l_{\rho}=31.7$ (after Liu et al., 1979 data on temperature profile above heated surface). Troitskaya et al. (2013) have confirmed good performance of these approximations of $K_{\mathrm{m}}$ and $K_{\rho}$.

Coupled sets of equations for wave-induced disturbances, Eqs. (66)-(68), and for mean velocity and density, Eqs. (69)(71), are solved numerically by grid method. The coupled boundary-value problem is solved by an implicit method representing modified Gauss method for band matrix (Forsythe and Moler, 1967). Figures 1a-f, 2a-f, and 3a-f show mean profiles of the velocity, density, vertical fluxes of momentum and mass, and turbulent exchange coefficients in MABL over harmonic wave, for the friction velocity $u_{*}=0.10 \mathrm{~cm} \mathrm{~s}^{-1}$, wave numbers $k=0.33,0.01,0.001 \mathrm{~cm}^{-1}$, and the surface wave steepness $\mathrm{ka}=0.1$. We have considered the cases of stable, neutral and unstable stratification in MABL with $\rho_{*} / \rho_{\mathrm{a}}== \pm 3 \times 10^{-4}$ and $k L=100,1$, and 0.35 in Figs. 1 , 2 , and 3 , respectively.

It follows from Fig. 1b that the wave-induced flux of momentum is almost the same for all types of stratification. The level of the effective wind-wave momentum transfer, where the flux profile has a cusp, is located lower than $L$, where stratification effects are negligible. It is also concluded that the wind-to-wave flux of momentum is positive, i.e., wind delivers momentum to waves, strengthening them and, in turn, slows down. This regime is typical for waves with the phase velocities $c$ slower than the wind speed $U$ (Miles, 1959). Generally, $U$ is taken equal to the wind speed $U_{10}$ at the reference level $h_{10}=10 \mathrm{~m}$. In terms of the friction velocity $u_{*}$, the condition $\frac{U}{c}>1$ takes the form $\frac{u_{*}}{c}>\sqrt{C_{D}} \approx 0.035$. Using relation Eq. (74) between the wave age $\frac{u_{*}}{c}$ and $k L$, this condition can be rewritten as

$L k>\frac{C_{D}}{\left(\rho_{*} / \rho_{\mathrm{a}}\right)}$.

In the cases $k L=1$ and $k L=0.35(k L \leq 1)$ shown in Figs. $2 b$ and $3 b$, the cusp in the vertical profile of the waveinduced flux of momentum is located at heights comparable with $L$. This profile, as well as the mean velocity profile, essentially depends on stratification. In strongly stable stratification, the momentum transfer between wind and waves is significantly weaker than in neutral and unstable stratifications.

If the criterion Eq. (80) does not hold, momentum can be transferred from waves to wind. Such winds induced by waves are often observed in the conditions of swell (see, e.g., Semedo et al., 2009). Here, the energy is transferred from waves to wind due to the stresses proportional to eddy viscosity $K_{\mathrm{m}}$ (Troitskaya, 1997). As seen in Fig. 3c, $K_{\mathrm{m}}$ in strongly stable stratification is significantly smaller than in neutral stratification. This effect essentially reduces the wave-induced momentum flux and therefore the speed of the wave-induced wind. 


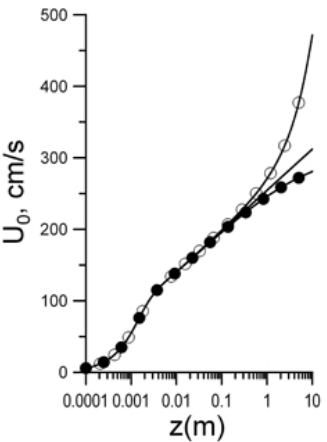

(a)

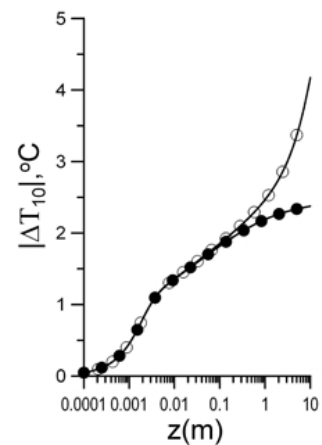

(d)

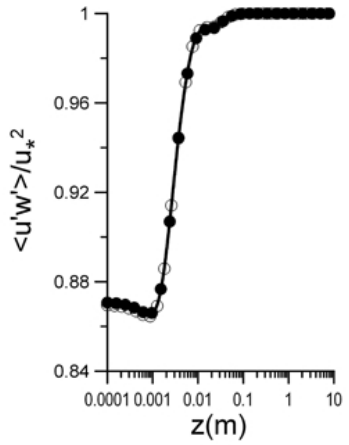

(b)

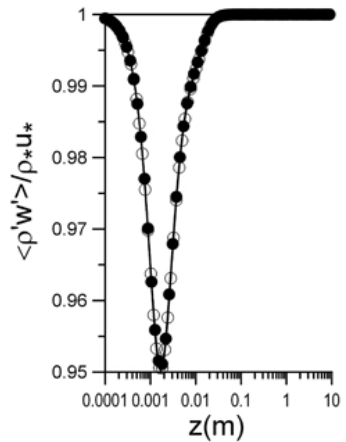

(e)

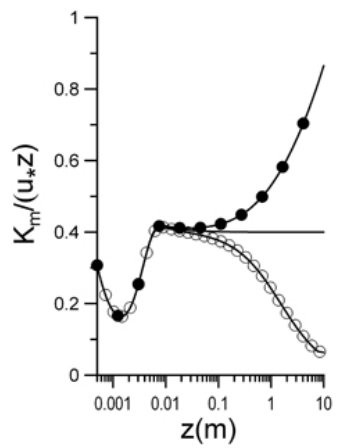

(c)

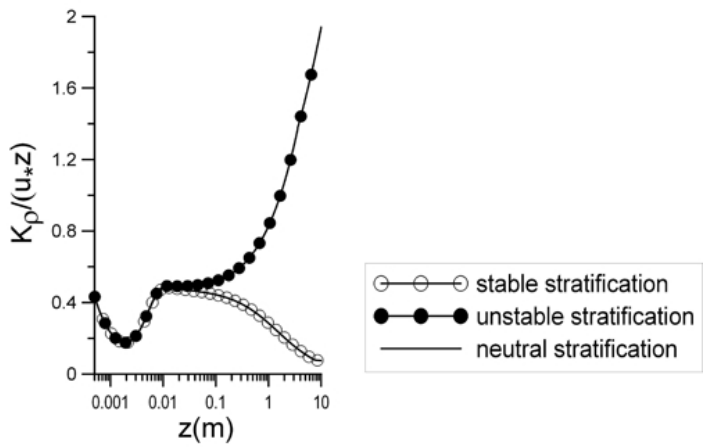

(f)

Fig. 1. Profiles of mean velocity (a) and temperature (d), normalized turbulent momentum (b) and mass (e) fluxes, normalized turbulent momentum (c) and mass (f) transfer coefficients. Friction velocity is $10 \mathrm{~cm} \mathrm{~s}^{-1}$, density scale $\rho_{*} / \rho_{\mathrm{a}}= \pm 3 \times 10^{-4}, k=0.33 \mathrm{~cm}^{-1}$, and $k L=100$.

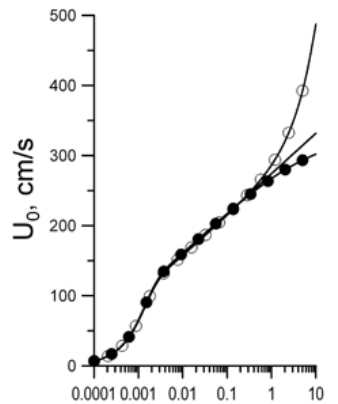

$z(m)$

(a)

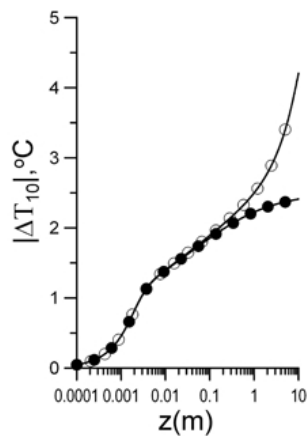

(d)

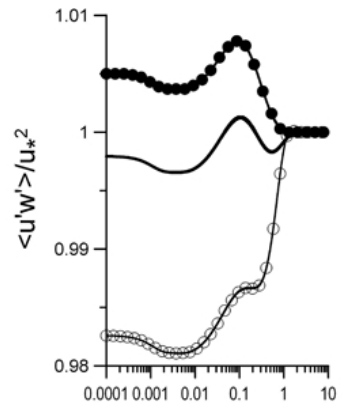

$z(m)$

(b)

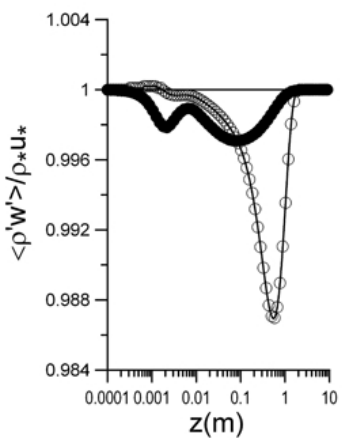

(e)

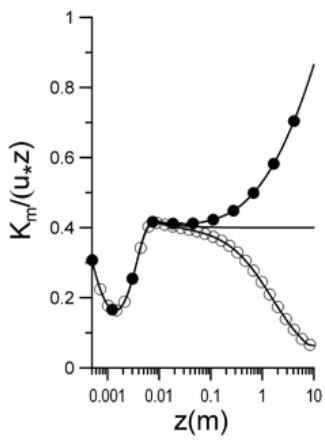

(c)

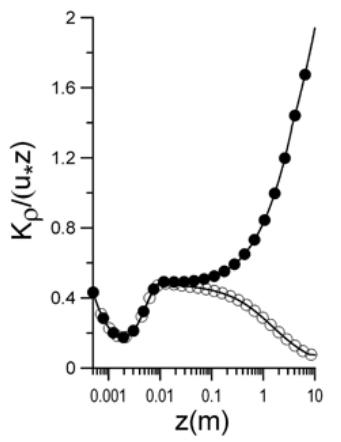

(f)

Fig. 2. The same as in Fig. 1 for $k L=1$. 


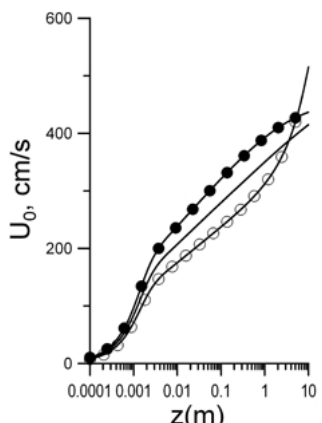

(a)

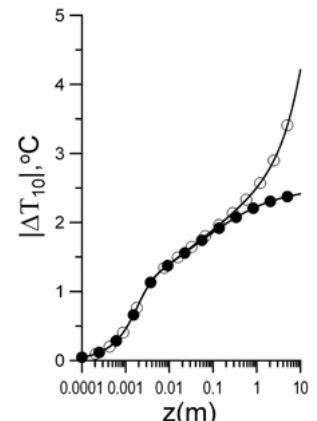

(d)

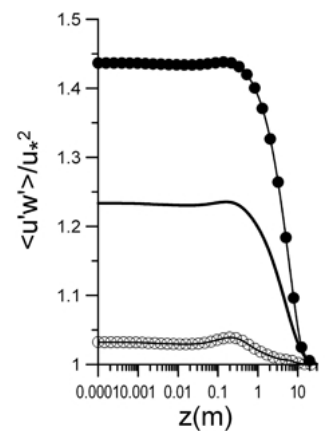

(b)

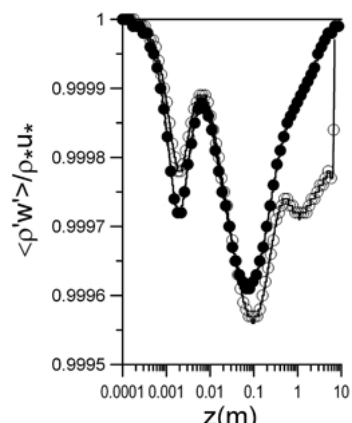

(e)

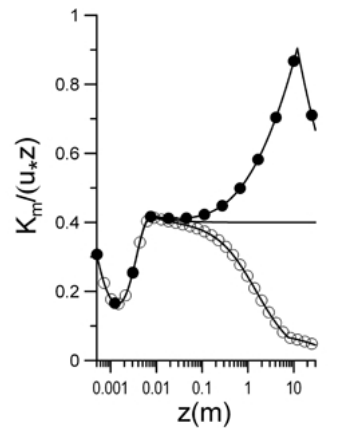

(c)

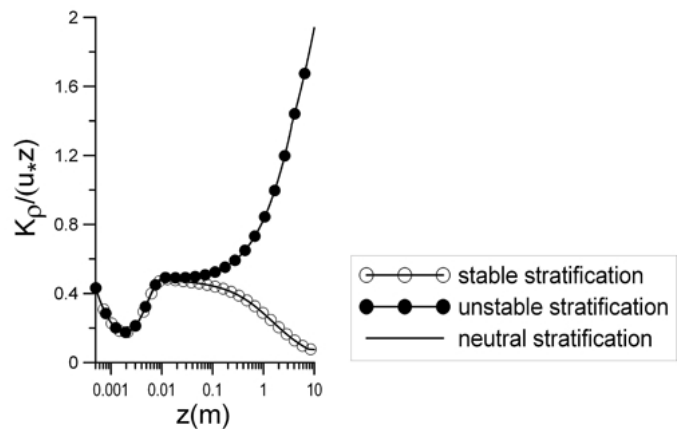

(f)

Fig. 3. The same as in Fig. 1 for $k L=0.35$.

It is worth noticing the effect of decreasing the turbulent mass flux close to the surface due to the wave mass flux (see Figs. 1-3e). The point is that the resonant interaction of waves with stratified shear flows in the presence of eddy viscosity and conductivity leads to irreversible reduction of the density gradient in the critical layers, i.e. regions with closed streamlines (see, e.g., Maslowe, 1972; Haberman, 1973; Troitskaya, 1991), which leads to the positive wave mass flux $P_{\text {wave }}(\eta)$ in Eq. (6). The decrease in the mass flux depends on the eddy conductivity $K_{\rho}$; while $K_{\rho}$ tends to zero, the density gradient in the critical layer also tends to zero. This effect is the main subject of the Maslowe (1972) theorem, which is an analog of the Batchelor (1956) theorem on the constant vorticity in a region with closed streamlines. In its turn, reducing the mean density gradient associated with this effect leads to reducing the density difference between the sea surface and reference level. According to Eq. (13), this leads to a slight increase in the eddy conductivity. One could expect that this effect is most pronounced in light winds and strong stratification in MABL.

To estimate significance of the considered effects, we calculated the temperature and velocity profiles for the smooth water surface and in the wavy surface with the same fluxes of momentum and mass. For simplicity, we assumed that the density stratification was due to the temperature gradient. The wave steepness was taken at $\mathrm{ka}=0.1$. Comparing Fig. panels $4 \mathrm{a}-\mathrm{c}$ with $\mathrm{d}-\mathrm{f}$ one can see that the relative contribution to the mean density profile due to the wave decreases with increasing friction velocity and does not exceed relative contribution to the mean velocity profile. These quantities are of the same order only for very low friction velocities and short waves. For example, for $u_{*}=5 \mathrm{~cm} \mathrm{~s}^{-1}$ and $k=1 \mathrm{~cm}^{-1}$, contributions to the temperature and velocity profiles are approximately $0.17^{\circ} \mathrm{C}$ and $10 \mathrm{~cm} \mathrm{~s}^{-1}$ for $\Delta T_{10}=2^{\circ} \mathrm{C}$ and $U_{10}=120 \mathrm{~cm} \mathrm{~s}^{-1}$ (Fig. 4a and d). For $u_{*}=10 \mathrm{~cm} \mathrm{~s}^{-1}$ and $k=0.33 \mathrm{~cm}^{-1}$, relative contribution to the temperature profile is an order of magnitude less than relative contribution to the velocity profile (see Fig. $4 \mathrm{~b}$ and e). For $u_{*}=10 \mathrm{~cm} \mathrm{~s}^{-1}$ and $k=0.001 \mathrm{~cm}^{-1}$, contribution to the temperature profile is negligibly small. Thus, the wave mass flux may often be neglected (as it was done by Makin and Mastenbroek, 1996, and Makin and Kudryavtsev, 1999).

As demonstrated in Sect. 2, the wind-to-wave momentum flux gives an additive to wind speed, $\Delta u$, which can be calculated by Eq. (26). Taking $K_{\text {mwave }}=K_{\mathrm{m}}$ yields

$$
\Delta u=\int_{0}^{\infty} \frac{\tau_{\mathrm{wave}}}{K_{\mathrm{m}}} \mathrm{d} z .
$$

A quantity $\Delta u$ can be treated as an integral characteristic of the wind-wave momentum exchange.

Examples of such dependence of $\Delta u$ on wave number for the fixed wave steepness $\mathrm{ka}=0.1$ are shown in Fig. 5 for 3 friction velocities $u_{*}=5,10,50 \mathrm{~cm} \mathrm{~s}^{-1}$ and $\rho_{*} / \rho_{\mathrm{a}}=$ $\pm 3.3 \times 10^{-4}$.

The wind speed $U_{10}$ and temperature difference $\Delta T_{10}$ at the reference level $h_{10}$ depend on the parameters of the wave; their values are given in Table 1. It can be seen from Table 1 

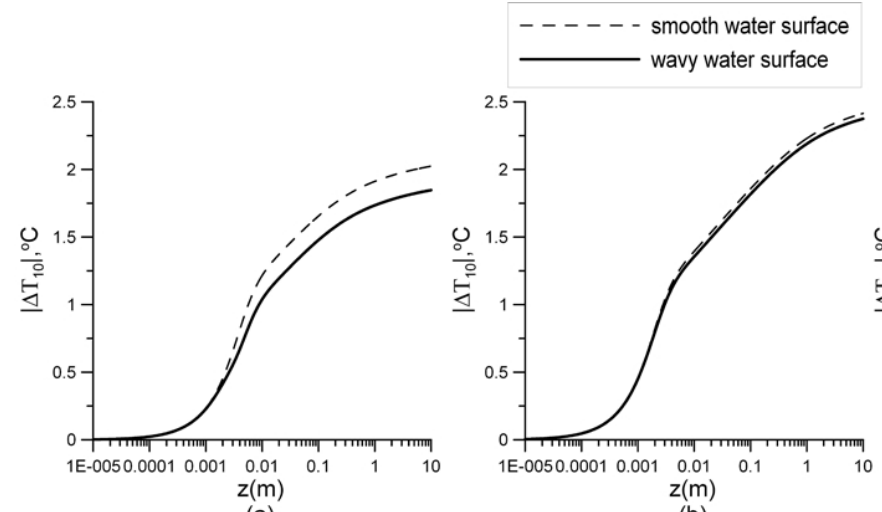

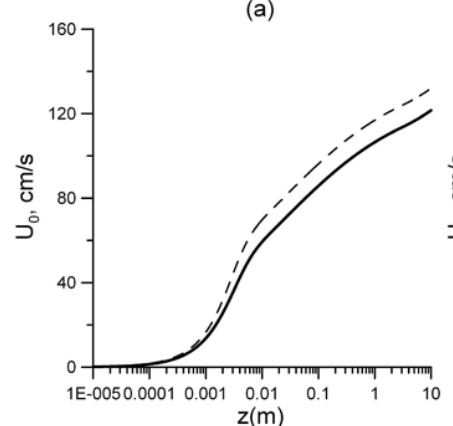

(d)

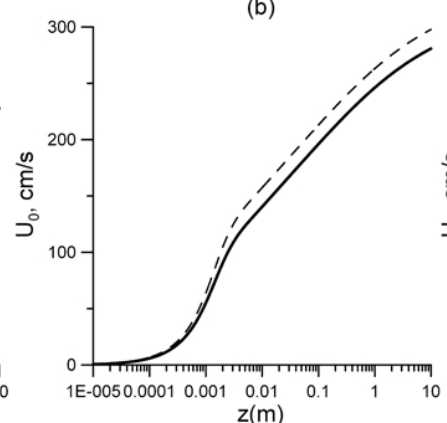

(e)

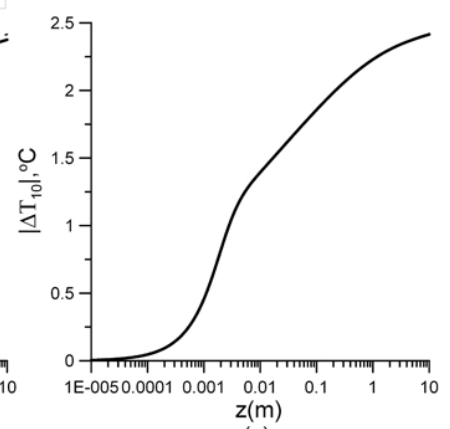

(c)

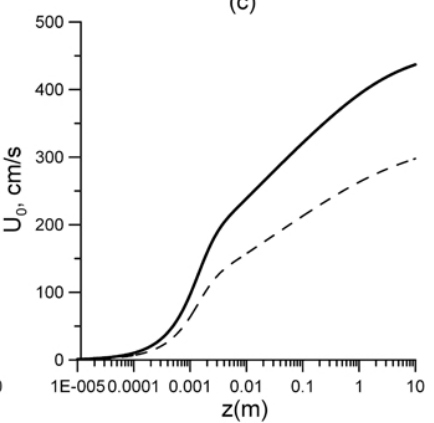

(f)

Fig. 4. Examples of the temperature (a,b,c) and velocity $(\mathbf{d}, \mathbf{e}, \mathbf{f})$ profiles over wavy and smooth water surface, $\mathrm{ka}=0.1 .(\mathbf{a}, \mathbf{d}) u_{*}=5 \mathrm{~cm} \mathrm{~s}{ }^{-1}$ and $k=1 \mathrm{~cm}^{-1}$, (b,e) $u_{*}=10 \mathrm{cms}^{-1}$ and $k=0.33 \mathrm{~cm}^{-1}$, and $(\mathbf{c}, \mathbf{f}) u_{*}=10 \mathrm{~cm} \mathrm{~s}^{-1}$ and $k=0.001 \mathrm{~cm}^{-1}$.

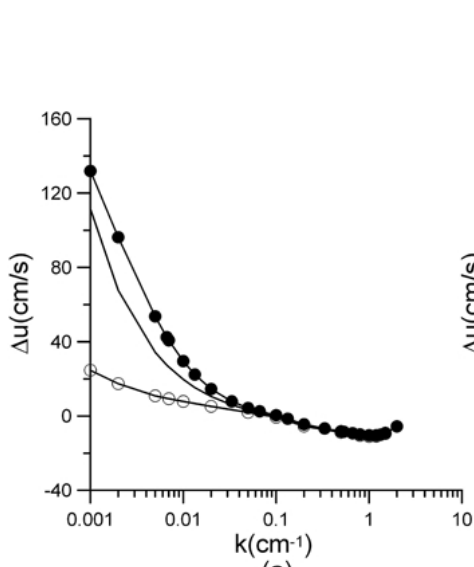

(a)

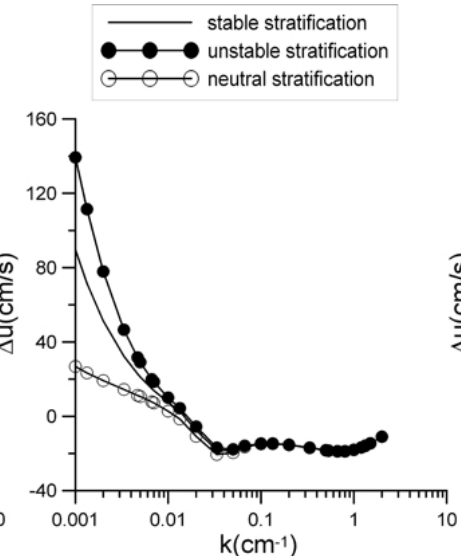

(b)

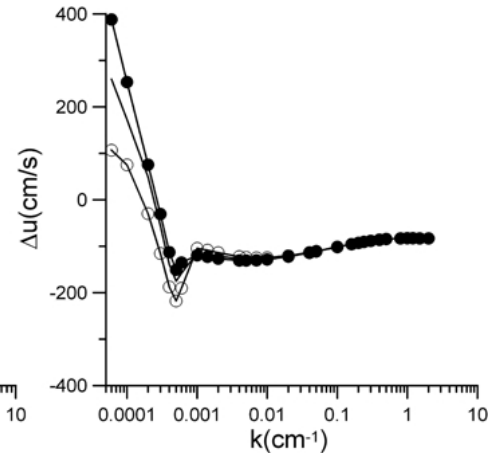

(c)

Fig. 5. Dependencies of the nonlinear additives to the wind velocity profiles on a wave number. Wave steepness $\mathrm{ka}=0.1,(\mathbf{a}) u_{*}=5 \mathrm{~cm} \mathrm{~s}{ }^{-1}$, (b) $u_{*}=10 \mathrm{~cm} \mathrm{~s}^{-1}$, and (c) $u_{*}=50 \mathrm{~cm} \mathrm{~s}^{-1}$.

that in neutral and unstable stratification the waves change wind speed significantly. Figure 5 demonstrates that the long waves give the maximum positive additive to the wind speed. This effect of acceleration of the wind in the presence of swell was noted by Kudryavtsev and Makin (2004), and observed in the field experiments by Semedo et al. (2009).

The dependencies of dimensionless additive to wind speed $\Delta u / u_{*}$ on wave age are shown in Fig. $6 \mathrm{a}-\mathrm{c}$ for $\rho_{*} / \rho_{\mathrm{a}}=$ $-3.3 \times 10^{-4} ; 0 ; 3.3 \times 10^{-4}$. The curves almost coincide in all figures, hence $\Delta u / u_{*}$ is a function of two parameters:

$$
\frac{\Delta u}{u_{*}}=U\left(\frac{u_{*}}{c}, \frac{\rho_{*}}{\rho_{\mathrm{a}}}\right) .
$$

Taking this into account, Eq. (74) yields

$$
\frac{\Delta u}{u_{*}}=U_{1}\left(L k, \frac{\rho_{*}}{\rho_{\mathrm{a}}}\right) .
$$




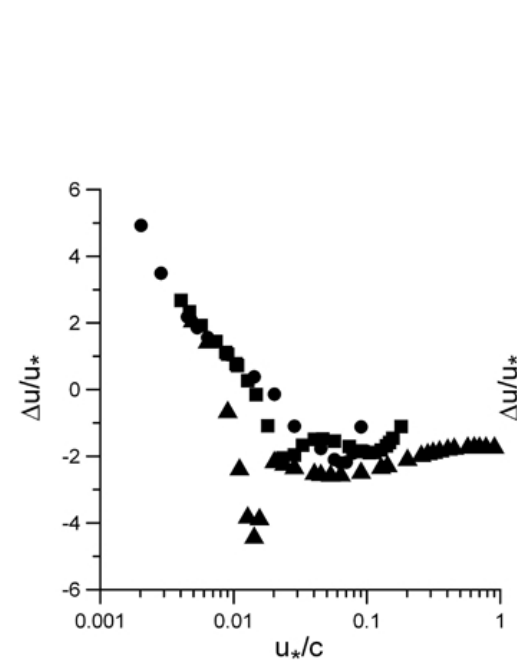

(a)

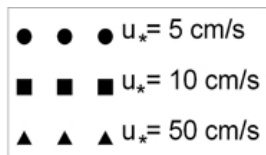

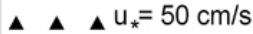

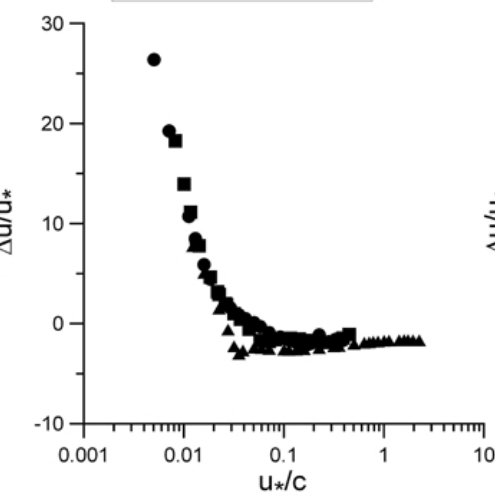

(b)

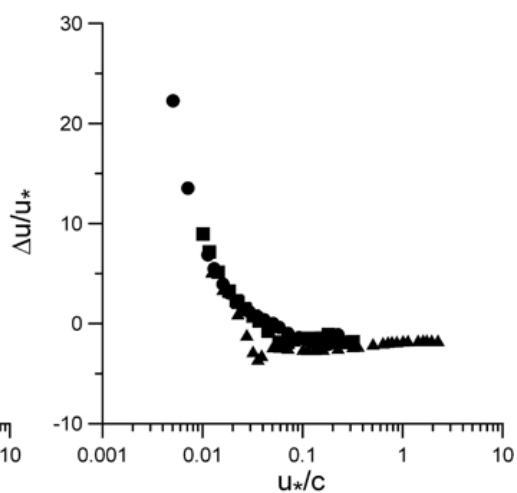

(c)

Fig. 6. Dependencies of the normalized nonlinear additives to the wind velocity $\Delta u / u_{*}$ on wave age in stable (a), neutrally stable (b) and unstable (c) stratification for $u_{*}=5 \mathrm{~cm} \mathrm{~s}^{-1}$ (circles), $u_{*}=10 \mathrm{~cm} \mathrm{~s}^{-1}$ (squares), and $u_{*}=50 \mathrm{~cm} \mathrm{~s}^{-1}$ (triangles).

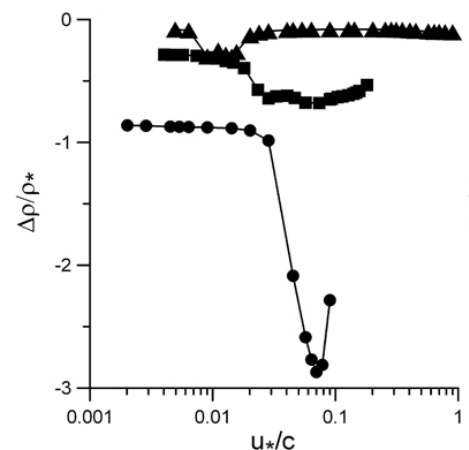

(a)

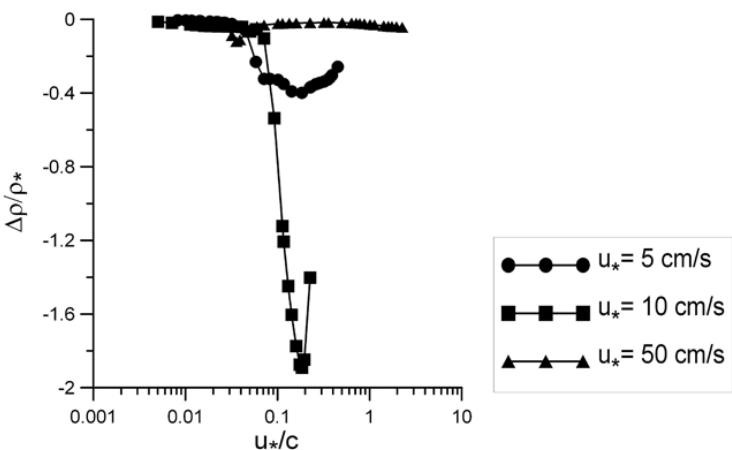

(b)

Fig. 7. Dependencies of the normalized nonlinear additives to the density $\Delta \rho / \rho_{*}$ on wave age in stable (a) and unstable (b) stratification.

Table 1. Range of values of the wind speed and temperature difference at the reference level due to changing wave parameters.

\begin{tabular}{lccc}
\hline$u_{*}, \mathrm{~cm} \mathrm{~s}^{-1}$ & 5 & 10 & 50 \\
$U_{10}, \mathrm{~cm} \mathrm{~s}^{-1}$, stable & $1.5 / 1.8$ & $3.2 / 3.6$ & \\
$U_{10}, \mathrm{~cm} \mathrm{~s}^{-1}$, neutral & $1.5 / 2.8$ & $3.1 / 4.1$ & \\
$U_{10}, \mathrm{~cm} \mathrm{~s}^{-1}$, unstable & $1.5 / 2.9$ & $3.2 / 5.1$ & $22.4 / 17.6$ \\
$\Delta T_{10},{ }^{\circ} \mathrm{C}$, stable & $2.6 / 2.7$ & 2.8 & \\
$\Delta T_{10},{ }^{\circ} \mathrm{C}$, unstable & $2.6 / 2.7$ & 2.8 & 3.1 \\
\hline
\end{tabular}

Decrease of the turbulent mass flux close to the water surface (presented in Figs. 1-3e) results in a negative additive to the average density profile $\Delta \rho$, which can be calculated from Eq. (31).
For $K_{\rho \text { wave }}(z)=K_{\rho}(z)$ it reads

$$
\Delta \rho=\int_{0}^{\infty} \frac{\tau_{\rho \text { wave }}(z)}{K_{\rho}(z)} \mathrm{d} z .
$$

Dependencies of a normalized density additive $\Delta \rho / \rho_{*}$ on wave age $\frac{u_{*}}{c}$ in stable and unstable stratification are shown in Fig. 7a and b. There is a strong dependence of $\Delta \rho / \rho_{*}$ on $u_{*}$. The additive to the mean density profile from the waveinduced mass flux, however, is small (see Fig. 4a-e) and may be neglected.

As $\Delta u$ depends on the wave amplitude, the exchange coefficients also depend on the wave parameters. Dependencies of a drag coefficient on the wave length are shown in Fig. 8a-c. The drag coefficient increases in the presence of the short waves and may decrease in the presence of the long waves. This agrees with the calculated mean wind speed profiles shown in Figs. 1-3a and momentum flux profiles shown in Figs. 1-3b. The short waves "extract" momentum from 


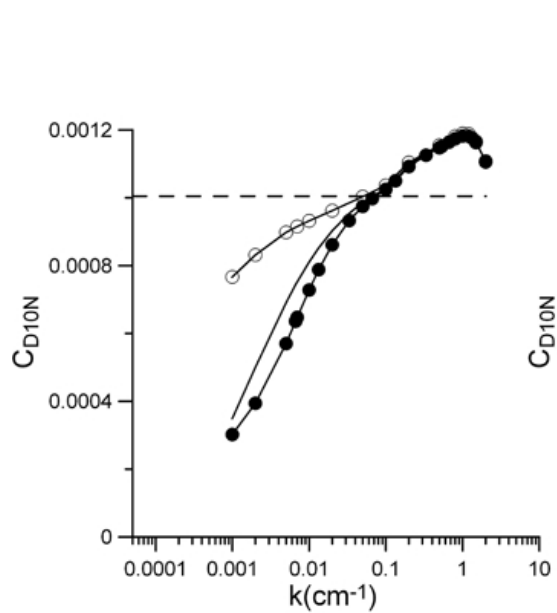

(a)

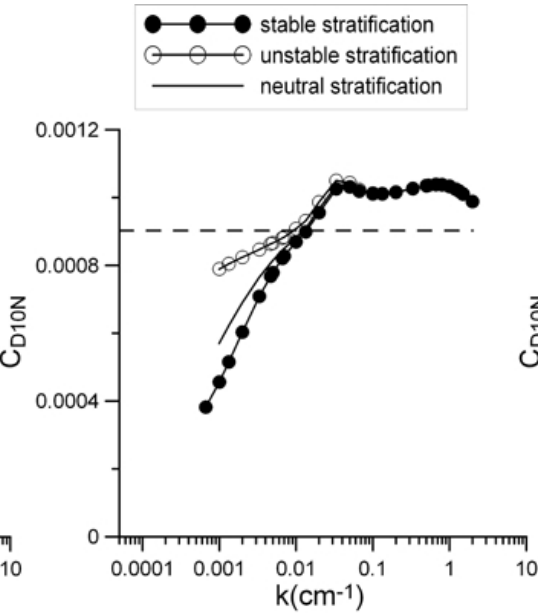

(b)

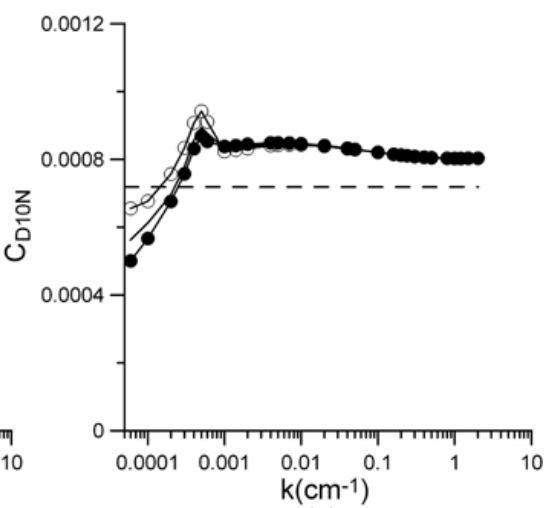

(c)

Fig. 8. Dependencies of the drag coefficient of the water surface on the wave length for $u_{*}=5 \mathrm{~cm} \mathrm{~s}^{-1}$ (a), $u_{*}=10 \mathrm{cms}^{-1}$ (b), $u_{*}=$ $50 \mathrm{cms}^{-1}(\mathbf{c})$.

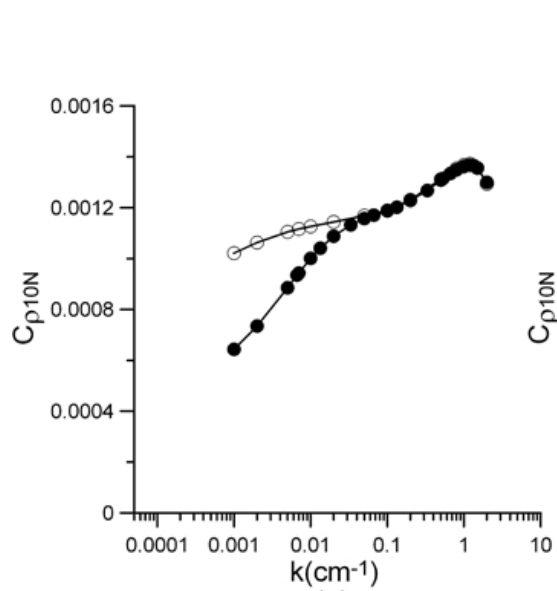

(a)

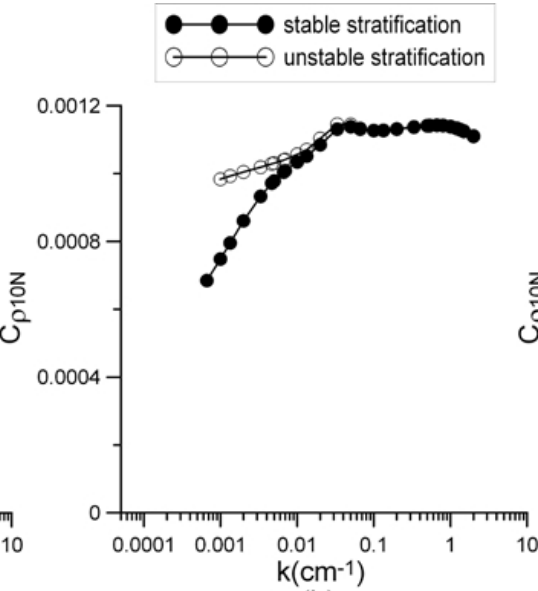

(b)

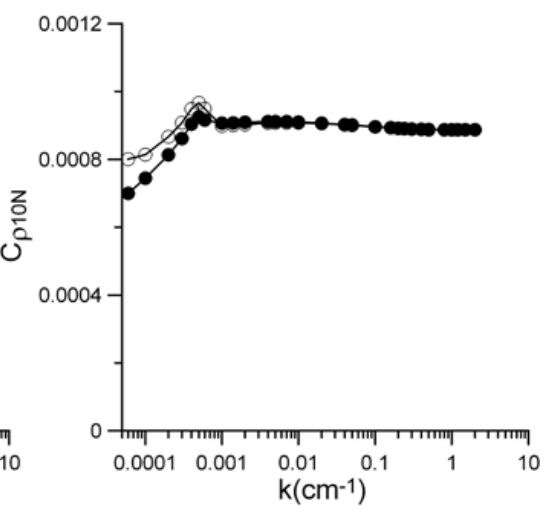

(c)

Fig. 9. Dependencies of the mass exchange coefficient of the water surface on the wave length for $u_{*}=5 \mathrm{~cm} \mathrm{~s}^{-1}$ (a), $u_{*}=10 \mathrm{cms}^{-1}$ (b), $u_{*}=50 \mathrm{cms}^{-1}$ (c).

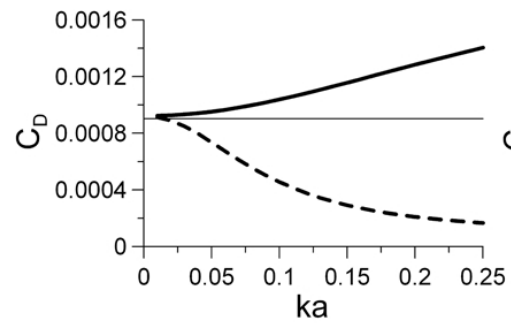

(a)

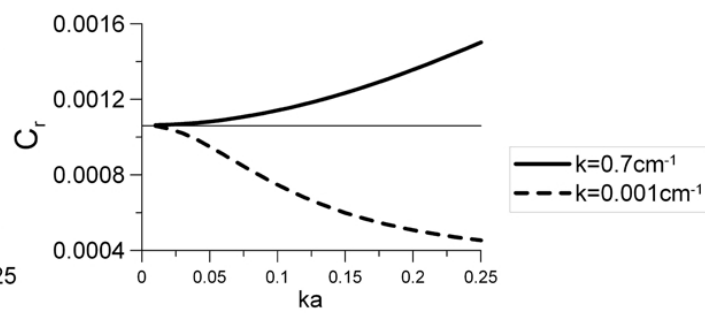

(b)

Fig. 10. Dependencies of the coefficients of aerodynamic resistance (a) and mass exchange (b) on the steepness of the wave for $u_{*}=$ $10 \mathrm{cms}^{-1}$. 
the wind, increasing surface drag, while the long waves deliver momentum to the wind, decreasing drag. According to Fig. 8a-c, this makes ultra-smooth flow possible. Dependencies of the mass transfer coefficient $C_{\rho}$ on wave number (Fig. 9a-c) are qualitatively analogous in agreement with Eq. (32) for $\Delta \rho=0$.

We explored dependencies of $C_{\mathrm{D} 10 \mathrm{~N}}$ and $C_{\rho 10 \mathrm{~N}}$ on the wave steepness for a fixed wave length and prescribed wind and stratification (Fig. 10). For the phenomenon of short waves increasing surface drag, steepness growth results in decrease of $C_{\mathrm{D} 10 \mathrm{~N}}$ and $C_{\rho 10 \mathrm{~N}}$.

\section{Conclusions}

This paper is the first part of our report on the momentum and buoyancy transfer in MABL over wavy water surface. Here we constructed a model based on a self-consistent problem for the wave-induced air perturbations and mean velocity and density fields. We explored the simplest case of harmonic waves propagating along the wind. It is shown within the model that a drag coefficient may either decrease or increase, depending on the wave length. Surface drag decrease is expected in the presence of swell, which can deliver momentum to wind. Drag decrease is more pronounced in unstable stratification. This is the result of exchange intensity reduction in stably stratified flow due to suppression of the turbulent pulsations. The case of a harmonic wave propagating along the wind considered in this paper is an idealization, but it is essential for analysis of peculiarities of air-sea interaction.

\section{Appendix A}

\section{List of symbols}

$\begin{array}{lll}\tau & - & \text { turbulent momentum flux } \\ \rho_{\mathrm{a}} & - & \text { air density } \\ \rho_{\mathrm{a} 0} & - & \text { air density on the surface } \\ u_{*} & - & \text { friction velocity } \\ H & - & \text { sensible heat } \\ C_{p} & - & \text { air heat capacity } \\ T_{*} & - & \text { constant, characterizing the flux of moisture in the air } \\ q_{*} & - & \text { constant, characterizing the flux of heat in the air } \\ l & - & \text { specific heat of evaporation } \\ h_{10} & - & \text { a reference level where meteorological } \\ & & \text { parameters are measured } \\ & & \text { (10m above the water surface) } \\ U_{10} & - & \text { wind speed at a reference level } h_{10} \\ T_{10} & - & \text { temperature at a reference level } h_{10} \\ q_{10} & - & \text { humidity at a reference level } h_{10} \\ C_{D}, C_{\mathrm{D} 10} & - & \text { drag coefficient } \\ C_{H} & - & \text { Stanton number } \\ C_{l} & - & \text { Dalton number } \\ C_{\rho}, C_{\rho 10} & - & \text { mass transfer coefficient } \\ P & - & \text { turbulent mass flux }\end{array}$

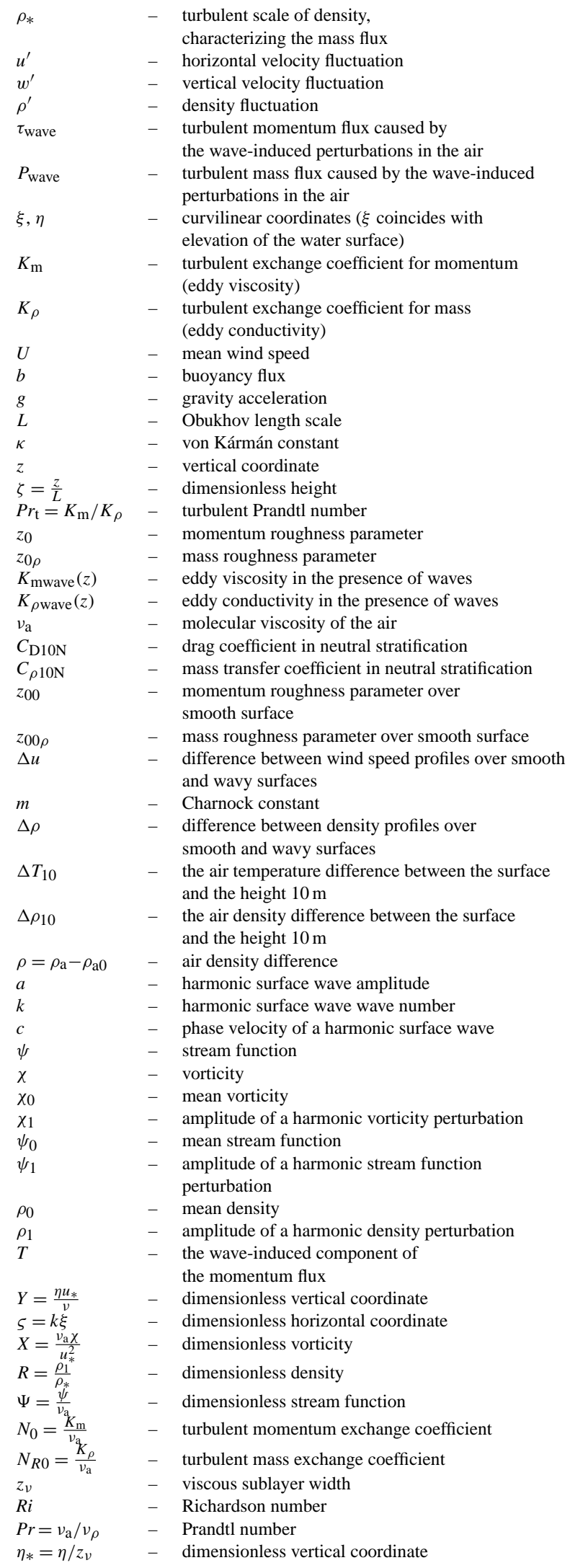


Acknowledgements. This work was supported by a grant from the Government of the Russian Federation under Contract No. 11.G34.31.0048; European Research Council Advanced Grant, FP7-IDEAS, 227915; RFBR grants 13-05-00865-a, 12-05-01064, 12-05-31435 mol_a, 12-05-33070 mol_a_ved;Federal Targeted Program "Scientific and scientific-pedagogical personnel of innovative Russia" for 2009-2013 GK No. 14.132.21.1384, GK No. 16.740.11.0673.

Edited by: I. Esau

Reviewed by: A. D. Jenkins and one anonymous referee

\section{References}

Batchelor, G. K.: On steady laminar flow with closed streamlines at large Reynolds number, J. Fluid Mech., 1, 177-190, 1956.

Batchelor, G. K.: An Introduction to Fluid Dynamics, Cambridge University Press, Cambridge, UK, 1967.

Brut, A., Butet, A., Durand, P., Caniaux, G., and Planton, S.: Airsea exchanges in the equatorial area from the EQUALANT99 dataset: Bulk parametrizations of turbulent fluxes corrected for airflow distortion, Q. J. Roy. Meteor. Soc., 131, 2497-2538, 2005.

Businger, J. A., Wyngaard, J. C., Izumi, Y., and Bradley, E. F.: Fluxprofile relationships in the atmospheric surface layer, J. Atmos. Sci., 28, 181-189, 1971.

Drennan, W. M., Zhang, J., French, J. R., McCormick, C., and Black, P. G.: Turbulent fluxes in the hurricane boundary layer. Part II: Latent heat flux, J. Atmos. Sci., 64, 1103-1115, 2007.

Druzhinin, O. A., Troitskaya, Y. I., and Zilitinkevich, S. S.: Direct numerical simulation of a turbulent wind over a wavy water surface, J. Geophys. Res., 117, C00J05, doi:10.1029/2011JC007789, 2012.

Fairall, C. W., Bradley, E. F., Hare, J. E., Grachev, A. A., and Edson, J. B.: Bulk parameterization of air-sea fluxes: updates and verification for the COARE algorithm, J. Climate, 16, 571-591, 2003.

Forsythe, G. E. and Moler, C. B.: Computer Solution of the Linear Algebraic Systems, Engelwood Cliffs, New Jersey, 1967.

Garratt, J. R.: Review of Drag Coefficients over Oceans and Continents, Mon. Weather Rev., 105, 915-929, 1977.

Haberman, R.: Wave-induced distortions of a slightly stratified shear flow: a nonlinear critical-layer effect, J. Fluid Mech., 58, 727-736, 1973.

Hsu, C. T., Hsu, E. Y., and Street, R. L.: On the structure of turbulent flow over a progressive water wave: theory and experiment in a transformed, wave-following coordinate system, J. Fluid Mech., 105, 87-117, 1981.

Hsu, C. T. and Hsu, E. Y.: On the structure of turbulent flow over a progressive water wave: theory and experiment in a transformed wave-following coordinate system. Part 2, J. Fluid Mech., 131, 123-153, 1983.

Janssen, P. A. E. M.: Wave-induced stress and the drag of air flow over sea waves, J. Phys. Oceanogr., 19, 745-754, 1989.

Janssen, P. A. E. M.: Effect of surface gravity waves on heat flux, ECMWF, Tech. Rep., 1-13, 1997.

Janssen, P. A. E. M. and Komen, G. J.: Effect of the atmospheric stability on the growth of surface gravity waves, Bound.-Lay. Meteorol., 32, 85-96, 1985.
Jenkins, A. D.: Quasi-linear eddy-viscosity model for the flux of energy and momentum to wind waves using conservation-law equations in a curvilinear coordinate system, J. Phys. Oceanogr., 22, 843-858, 1992.

Kudryavstev, V. N. and Makin, V. K.: Impact of swell on the marine atmospheric boundary layer, J. Phys. Oceanogr., 34, 934-949, 2004.

Liu, W. T., Katsaros, K. B., and Businger, J. A.: Bulk parameterization of air-sea exchanges of heat and water vapor including the molecular constraints at the interface, J. Atmos. Sci., 36, 1722$1735,1979$.

Makin, V. K. and Kudryavtsev, V. N.: Coupled sea surfaceatmosphere model. Part 1. Wind over waves coupling, J. Geophys. Res., 104, 7613-7623, 1999.

Makin, V. K. and Mastenbroek, C.: Impact of waves on air-sea exchange of sensible heat and momentum, Bound.-Lay. Meteorol., 79, 279-300, 1996.

Makin, V. K., Kudryavtsev, V. N., and Mastenbroek, C.: Drag of the sea surface, Bound.-Lay. Meteorol., 73, 159-182, 1995.

Maslowe, S. A.: The generation of clear air turbulence by nonlinear waves, Stud. Appl. Math., 51, 1-16, 1972.

Miles, J. W.: On the Generation of Surface Waves by Shear Flows. Part 2, J. Fluid Mech., 6, 568-582, 1959.

Monin, A. S. and Yaglom, A. M.: Statistical fluid dynamics. V.1, Gidrometeoizdat, St. Petersburg, 1992.

Ocampo-Torres, F. J., Donelan, M. A., Merzi, N., and Jia, F.: Laboratory measurements of mass transfer of carbon dioxide and water vapour for smooth and rough flow conditions, Tellus, 46B, 16-32, 1994.

Plant, W. J.: A relationship between wind stress and wave slope, J. Geophys. Res., 87, 1961-1967, 1982.

Reutov, V. P. and Troitskaya, Yu. I.: Nonlinear effects due to water wave interactions with a turbulent wind, Izv. Atmos. Ocean. Phy., 31, 792-801, 1996.

Semedo, A., Saetra, Ø., Rutgersson, A., Kahma, K. K., and Pettersson, H.: Wave-Induced Wind in the Marine Boundary Layer, J. Atmos. Sci., 66, 2256-2271, 2009.

Smith, S. S. D., Fairall, C. W., Geernaert, G. L., and Hasse, L.: Air-sea fluxes - 25 years of progress, Bound.-Lay. Meteorol., 78, 247-290, 1996.

Smol'yakov, A. V.: Quadrupole radiation spectrum of plane turbulent boundary layer, Sov. Phys. Acoust., 19, 271-276, 1973.

Sullivan, P. P., McWilliams, J. C., and Moeng, C.-H.: Simulation of turbulent flow over idealized water waves, J. Fluid Mech., 404, 47-85, 2000.

Sullivan, P. P., Edson, J., Hristov, T., and McWilliams, J. C.: Largeeddy simulations and observations of atmospheric marine boundary layers above nonequilibrium surface waves, J. Atmos. Sci., 65, 1225-1245, 2008.

Troitskaya, Yu. I.: Viscous diffusion nonlinear critical layer in a stratified shear flow, J. Fluid Mech., 233, 25-48, 1991.

Troitskaya, Yu. I.: Modulation mechanism of the growth rate for short surface waves generated by turbulent wind, Izvestiya, Atmos. Oceanic Phys., 33, 525-535, 1997.

Troitskaya, Yu. I. and Rybushkina, G. V.: Quasi-linear model of interaction of surface waves with strong and hurricane winds, Izv. Atmos. Ocean. Phys., 44, 621-645, 2008.

Troitskaya, Yu. I., Sergeev, D. A., Ermakova, O. S., and Balandina, G. N.: Statistical properties of the atmospheric turbulent 
boundary layer over steep surface waves, Dokl. Earth Sci., 433, 922-926, 2010a.

Troitskaya, Yu. I., Sergeev, D. A., Ermakova, O. S., and Balandina G. N.: Fine structure of the turbulent atmospheric boundary layer over the water surface, Izv. Atmos. Ocean. Phy., 46, 109-120, 2010 b.

Troitskaya, Yu. I., Sergeev, D. A., Ermakova, O. S., and Balandina, G.N.: Statistical parameters of the air turbulent boundary layer over steep water waves measured by the DPIV technique, J. Phys. Oceanogr., 41, 1421-1454, 2011.

Troitskaya, Yu. I., Ezhova, E. V., Sergeev, D. A., Kandaurov, A. A., Baidakov, G. A., Vdovin, M. I., and Zilitinkevich, S. S.: Momentum and buoyancy transfer in atmospheric turbulent boundary layer over wavy water surface - Part 2: Wind-wave spectra, Nonlin. Processes Geophys., 20, 841-856, doi:10.5194/npg-20841-2013, 2013.
Weil, A., Eymard, L., Caniaux, G., Hauser, D., Planton, S., Dupius, H., Brut, A., Guerin, C., Nacas, P., Butet, A., Cloche, S., Pedreoros, R., Durand, P., Bourras, D., Giordani, H., Lachaud, G., and Bouhours G.: Toward a better determination of turbulent airsea fluxes from several experiments, J. Climate, 16, 600-618, 2003.

Yang, D. and Shen, L.: Direct-simulation-based study of turbulent flow over various waving boundaries, J. Fluid Mech., 650, 131$180,2010$.

Zeng, X., Zhao, M., and Dickinson, R. E.: Comparison of bulk aerodynamic algorithms for the computation of sea surface fluxes using the TOGA COARE and TAO data, J. Climate, 11, 26282644, 1998.

Zilitinkevich, S. S.: Theoretical model of turbulent penetrative convection, Izvestiya AN SSSR, FAO, 23, 593-610, 1976. 